\title{
Unveiling community patterns and trophic niches of tropical and temperate ants using an integrative framework of field data, stable isotopes and fatty acids
}

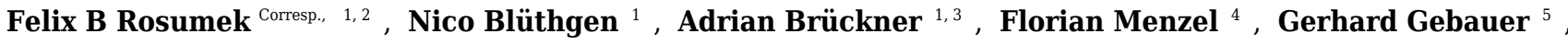 \\ Michael Heethoff ${ }^{\text {Corresp. } 1}$ \\ 1 Ecological Networks, Technische Universität Darmstadt, Darmstadt, Germany \\ 2 Department of Ecology and Zoology, Federal University of Santa Catarina, Florianópolis, Brazil \\ 3 Division of Biology and Biological Engineering, California Institute of Technology, Pasadena, United States \\ 4 Institute of Organismic and Molecular Evolution, Johannes-Gutenberg Universität Mainz, Mainz, Germany \\ 5 BayCEER - IBG, Universität Bayreuth, Bayreuth, Germany \\ Corresponding Authors: Felix B Rosumek, Michael Heethoff \\ Email address: rosumek@hotmail.com, heethoff@bio.tu-darmstadt.de
}

Background. The use and partitioning of trophic resources is a central aspect of community function. On the ground of tropical forests, dozens of ant species may be found together, and ecological mechanisms should act to allow such coexistence. One hypothesis states that niche specialization is higher in the tropics, compared to temperate regions. However, trophic niches of most species are virtually unknown. Several techniques might be combined to study trophic niche, such as field observations, fatty acid analysis (FAA) and stable isotope analysis (SIA). In this work, we combine these three techniques to unveil partitioning of trophic resources in a tropical and a temperate community. We describe patterns of resource use, compare them between communities, and test correlation and complementarity of methods to unveil both community patterns and species' niches. Methods. Resource use was assessed with seven kinds of bait representing natural resources available to ants. Neutral lipid fatty acid (NLFA) profiles, and $\delta^{15} \mathrm{~N}$ and $\delta^{13} \mathrm{C}$ isotope signatures of the species were also obtained. Community patterns and comparisons were analyzed with clustering, correlations, multivariate analyses and interaction networks. Results. Resource use structure was similar in both communities. Niche breadths $\left(H^{\prime}\right)$ and network metrics $\left(Q\right.$ and $\left.H_{2}{ }^{\prime}\right)$ indicated similar levels of generalization between communities. A few species presented more specialized niches, such as Wasmannia auropunctata and Lasius fuliginosus. Stable isotope signatures and NLFA profiles also indicated high generalization, although the latter differed between communities, with temperate species having higher amounts of fat and proportions of C18:1n9. Bait use and NLFA profile similarities were correlated, as well as species' specialization indexes $\left(d^{\prime}\right)$ for the two methods. Similarities in $\delta^{15} \mathrm{~N}$ and bait use, and in $\delta^{13} \mathrm{C}$ 
and NLFA profiles, were also correlated. Discussion. Our results agree with the recent view that specialization levels do not change with latitude or species richness. Partition of trophic resources alone does not explain species coexistence in these communities, and might act together with behavioral and environmental mechanisms. Temperate species presented NLFA patterns distinct from tropical ones, which may be related to environmental factors. All methods corresponded in their characterization of species' niches to some extent, and were robust enough to detect differences even in highly generalized communities. However, their combination provides a more comprehensive picture of resource use, and it is particularly important to understand individual niches of species. FAA was applied here for the first time in ant ecology, and proved to be a valuable tool due to its combination of specificity and temporal representativeness. We propose that a framework combining field observations with chemical analysis is valuable to understand resource use in ant communities. 
1 Unveiling community patterns and trophic niches of tropical and

2 temperate ants using an integrative framework of field data, stable

3 isotopes and fatty acids

4

5 Felix Baumgarten Rosumek ${ }^{1,2}$, Nico Blüthgen', Adrian Brückner ${ }^{1,3}$, Florian Menzel ${ }^{4}$,

6 Gerhard Gebauer ${ }^{5}$, Michael Heethoff ${ }^{1}$

7

8 1Ecological Networks, Technische Universität Darmstadt, Darmstadt, Germany

9 2Department of Ecology and Zoology, Federal University of Santa Catarina, Florianópolis,

10 Brazil

11 3Division of Biology and Biological Engineering, California Institute of Technology,

12 Pasadena, USA

13 4Institute of Organismic and Molecular Evolution, Johannes Gutenberg-Universität Mainz,

14 Mainz, Germany

15 5BayCEER - IBG, Universität Bayreuth, Bayreuth, Germany.

16

17 Corresponding authors: Felix Baumgarten Rosumek and Michael Heethoff.

E-mail addresses: rosumek@hotmail.com; heethoff@bio.tu-darmstadt.de.

20

21

22 


\section{Abstract}

25 Background. The use and partitioning of trophic resources is a central aspect of community 26 function. On the ground of tropical forests, dozens of ant species may be found together, and 27 ecological mechanisms should act to allow such coexistence. One hypothesis states that niche 28 specialization is higher in the tropics, compared to temperate regions. However, trophic niches of 29 most species are virtually unknown. Several techniques might be combined to study trophic 30 niche, such as field observations, fatty acid analysis (FAA) and stable isotope analysis (SIA). In 31 this work, we combine these three techniques to unveil partitioning of trophic resources in a 32 tropical and a temperate community. We describe patterns of resource use, compare them 33 between communities, and test correlation and complementarity of methods to unveil both 34 community patterns and species' niches.

35 Methods. Resource use was assessed with seven kinds of bait representing natural resources 36 available to ants. Neutral lipid fatty acid (NLFA) profiles, and $\delta^{15} \mathrm{~N}$ and $\delta^{13} \mathrm{C}$ isotope signatures 37 of the species were also obtained. Community patterns and comparisons were analyzed with 38 clustering, correlations, multivariate analyses and interaction networks.

39 Results. Resource use structure was similar in both communities. Niche breadths $\left(H^{\prime}\right)$ and 40 network metrics $\left(Q\right.$ and $\mathrm{H}_{2}$ ) indicated similar levels of generalization between communities. A 41 few species presented more specialized niches, such as Wasmannia auropunctata and Lasius 42 fuliginosus. Stable isotope signatures and NLFA profiles also indicated high generalization, 43 although the latter differed between communities, with temperate species having higher amounts 44 of fat and proportions of C18:1n9. Bait use and NLFA profile similarities were correlated, as 
45 well as species' specialization indexes $\left(d^{\prime}\right)$ for the two methods. Similarities in $\delta^{15} \mathrm{~N}$ and bait use, 46 and in $\delta^{13} \mathrm{C}$ and NLFA profiles, were also correlated.

47 Discussion. Our results agree with the recent view that specialization levels do not change with 48 latitude or species richness. Partition of trophic resources alone does not explain species coexistence in these communities, and might act together with behavioral and environmental mechanisms. Temperate species presented NLFA patterns distinct from tropical ones, which may be related to environmental factors. All methods corresponded in their characterization of species' niches to some extent, and were robust enough to detect differences even in highly generalized communities. However, their combination provides a more comprehensive picture of resource use, and it is particularly important to understand individual niches of species. FAA was applied here for the first time in ant ecology, and proved to be a valuable tool due to its combination of specificity and temporal representativeness. We propose that a framework combining field observations with chemical analysis is valuable to understand resource use in ant communities.

\section{Introduction}

The use and partitioning of trophic resources is a central aspect of community other fundamental interactions such as competition and mutualism (Polis \& Strong, 1996; Reitz

64 species coexistence, and may ultimately link to evolutionary processes of adaptation and 65 character displacement (Schluter, 2000).

Ants (Hymenoptera: Formicidae) are among the most abundant groups of invertebrates in terrestrial ecosystems, presenting a wide range of feeding habits, nesting sites, and interactions 
68 with organisms from all trophic levels. In general they are regarded as omnivorous, feeding on a

69 combination of living prey, dead arthropods, seeds and plant exudates (Blüthgen \& Feldhaar,

70 2010; Lanan, 2014). On the ground of tropical forests, dozens of species may coexist at the same

71 spot, which raises the question: how ecologically different are these species? Although the role

72 of interspecific competition in ant communities has recently been hotly debated (Cerdá, Arnan \&

73 Retana, 2013), the combination of high species richness with high biomass may lead to

74 evolutionary pressure for more diversified niches. MacArthur (1972) suggested that

75 specialization increases in tropical communities and, as a result, more species can coexist.

76 However, this idea was put in question by recent studies (Schleuning et al., 2012; Morris et al.,

77 2014; Frank et al., 2018). For ants, behavioral and environmental mechanisms of coexistence

78 have been proposed (Cerdá, Retana \& Cros, 1997; Andersen, 2000; Parr \& Gibb, 2012). The use

79 of food resources itself is surprisingly understudied, and trophic niches of most species remain

80 poorly known. This is particularly evident in rich tropical communities (Rosumek, 2017), but

81 also true for some temperate species (Lanan, 2014).

82 Field observations are the most straightforward way of gathering information, but there

83 are trade-offs between the number of species studied (e.g. single species natural history vs.

84 community patterns; Medeiros \& Oliveira, 2009; Houadria et al., 2015), the number of resources

85 assessed (e.g. protein/sugar comparisons vs. all resources collected by workers; Kaspari \&

86 Yanoviak, 2001; Lopes, 2007) and the sampling intensity (e.g. seasonal studies vs. temporal

87 “snapshots”; Albrecht \& Gotelli, 2001; Rosumek, 2017). Moreover, many species present cryptic

88 habits, and the sheer complexity of interactions makes the assessment of trophic niches a

89 laborious task. Baiting is a method widely used in ant ecology to assess communities and infer

90 resource use (Bestelmeyer et al., 2000), but it is affected by the aforementioned drawbacks. 
Several techniques have been applied in ecology to deal with these issues, among them

92

93

94

95

96

97

98

99

100

101

102

103

104

105

106

108

109

110

111

112

113

stable isotope analysis (SIA) and fatty acid analysis (FAA). Indirect techniques could be faster and reduce fieldwork effort, but also rely on several assumptions to interpret their results. Since every method has its assets and caveats, the choice depends on the nature of the questions being asked (Birkhofer et al., 2017). However, this also works the other way around: complementary methods can be combined to provide a detailed and integrative perspective on the community being studied.

Stable isotopes have been widely applied to address several questions in ant biology (Feldhaar, Gebauer \& Blüthgen, 2010). Most commonly used are the relative abundance of heavy nitrogen $\left(\delta^{15} \mathrm{~N}\right)$ and carbon $\left(\delta^{13} \mathrm{C}\right)$ (Hyodo, 2015). $\delta^{15} \mathrm{~N}$ increases predictably when one organism consumes another, thus indicates whether species are at top or bottom of the food web (Heethoff \& Scheu, 2016). $\delta^{13} \mathrm{C}$ could be used to distinguish between main carbon sources at the bottom of the food web, because $\mathrm{C}_{3}, \mathrm{C}_{4}$ and CAM plants have different signatures (O'Leary, 1988; Gannes, Del Rio \& Koch, 1998). SIA provides time-representative clues about trophic position, but limited information on specific food sources or feeding behaviors. For instance, if two species feed exclusively on primary consumers, they will have similar $\delta^{15} \mathrm{~N}$, regardless of what prey items they actually consume, or whether the food is obtained through predation or scavenging. As such, stable isotope signatures are not suitable to calculate niche breadth or overlap, or to be analyzed as species-resources interaction networks.

Fatty acids obtained from the diet are mainly stored as neutral lipid fatty acids (NLFAs) in the fat body of insects. Some fatty acids can be synthesized de novo by organisms, from carbohydrates or other fatty acids. Synthesis of C16:0, C18:0 and C18:1n9 (palmitic, stearic and oleic acids) is widespread, and they are the most abundant NLFAs in insects (Stanley-Samuelson 
114 et al., 1988; but see Thompson, 1973). Ability to synthesize other NLFAs is highly variable

115 among taxonomic groups, such as C18:2n6 (linoleic acid; Malcicka, Visser \& Ellers, 2018).

116 When fatty acids are reliably assigned to specific food sources, they may act as biomarkers

117 (Ruess \& Chamberlain, 2010). Even when such biomarkers are not identified, all fatty acids

118 assimilated without modification (i.e. through direct trophic transfer) influence the composition

119 of the fat reserves, including the relative amounts of de novo-synthesized NLFAs. Hence, the

120 stored fat preserves information on ingested carbon sources, and NLFA profiles can be compared

121 to infer niche differences (Budge, Iverson \& Koopman, 2006). However, the application of FAA

122 in field studies of terrestrial organisms still is limited. Most studies focused on soil detritivores,

123 such as collembolans and nematodes (Ruess et al., 2007; Haubert et al., 2009; Ngosong et al.,

124 2009). So far, FAA was not used to study trophic ecology of ants.

125 In this work, we combine field observations with SIA and FAA to unveil the use and

126 partitioning of trophic resources in a tropical and a temperate epigeic ant community. Our main

127 goal is to describe patterns for each community and test differences between communities and

128 methods. Specifically, we aim to: (1) assess use of multiple resources, stable isotope signatures

129 and NLFA profiles of the most abundant species in both communities; (2) compare patterns

130 between communities using descriptive and statistical approaches; (3) test whether different

131 methods provide convergent or complementary information on patterns of resource use.

\section{Materials \& Methods}

134 Baiting

135 Fieldwork in Brazil was carried out in Florianópolis (Desterro Conservation Unit, 136 27031'38"S, 48030'15"W, altitude ca. $250 \mathrm{~m}$ ), in December 2015 and January 2016, under 
137 sampling permit SISBIO 51173-1 (ICMBio), and export permits 15BR019038/DF and

138 17BR025207/DF (IBAMA). The vegetation consists in secondary Atlantic forest with at least 60

139 years of regeneration. High rainfall rate along the coast result in high productivity, ant species

140 richness, and a tropical aspect for the Atlantic forest even at higher latitudes such as in our work

141 (Silva \& Brandão, 2014). In Germany, it was carried out in Darmstadt (Prinzenberg, 4950'14"N,

$14208^{\circ} 40^{\prime} 01^{\prime \prime E}$, altitude ca. $250 \mathrm{~m}$ ), in July 2015 (no permits needed there). The vegetation consists

143 in patches of mixed forest, beech forest and orchards, which were all covered by the sample grids.

144 Sampling design followed similar protocols in both sites (Table 1). Seven baits types

145 were offered as proxies for resources that are widely used by ants in general (Kaspari, 2000;

146 Blüthgen \& Feldhaar, 2010; Lanan, 2014; for a full description of baits, see Supplemental

147 document S1). Sample points were distributed in grids and separated by $10 \mathrm{~m}$. In each sample

148 session, only a single bait was offered per point, and baits types were randomized among points.

149 Baits were set up in transparent plastic boxes and retrieved after 90 minutes. This procedure was

150 repeated in different days until all baits types had been offered in each point (twice in Brazil).

151 The design was based on Houadria et al. (2015) and evaluates use of multiple resources,

152 differing from a typical cafeteria experiment, which is designed to assess preferred resources

153 (Krebs, 1999).

154

155 Pitfall sampling

156 We performed a concomitant pitfall assessment to verify whether bait records represented 157 well the epigeic community (Table 1). One vial per sample point was previously buried to avoid 158 the digging-in effect (Greenslade 1973), and replaced after collection for the next round. Pitfall 
159 and bait sampling were not performed simultaneously at the same point. Vials were buried at

160 ground level, had $6 \mathrm{~cm}$ diameter and $150 \mathrm{ml}$ volume, and contained $40 \mathrm{ml}$ propylene glycol $50 \%$.

161

162 Fatty acid analysis (FAA)

163 In Brazil, samples were obtained from baits and complemented by colony sampling in

164 November 2017. We only used ants from melezitose, sucrose and seed baits, to avoid 165 interference of bait lipids. In Germany, they were obtained by colony sampling between July and 166 August 2017. Samples were frozen at $-18^{\circ} \mathrm{C}$ directly from the field. Total lipids were extracted 167 from the ants whole body using $1 \mathrm{ml}$ chloroform:methanol solution, $2: 1(\mathrm{v} / \mathrm{v})$. The solution was 168 applied to SiOH-columns and the neutral parcel (= mono-, di-, and triglycerides) eluted with 4 $169 \mathrm{ml}$ chloroform. Samples were analyzed with Gas chromatography-Mass spectrometry (GC-MS), 170 following the same procedures described in Rosumek et al. (2017). NLFA amounts were 171 obtained comparing their proportions to an internal standard $\left(\mathrm{C} 19: 0\right.$ in methanol; $\rho_{\mathrm{i}}=220$ $172 \mathrm{ng} / \mu \mathrm{l}$ ). Ants were subsequently dried to obtain their lean dry weight (= without lipids).

173

174 Stable isotope analysis (SIA)

$175 \quad$ Ants collected in baits and conserved in ethanol $70 \%$ were used to analyze $\delta^{15} \mathrm{~N}$ and $\delta^{13} \mathrm{C}$.

$176 \mathrm{C}$ and $\mathrm{N}$ isotope abundances were measured in a dual element analysis mode with an elemental 177 analyzer coupled to a continuous flow isotope ratio mass spectrometer (EA-IRMS) as described 178 in Bidartondo et al. (2004). Relative abundances were calculated following the equation: $\delta_{\mathrm{x}}=$ $179\left(\mathrm{R}_{\text {sample }} / \mathrm{R}_{\text {standard }}-1\right) \times 1000$ [\%o], where $\mathrm{R}$ denotes the ratio between heavy and light isotopes of 180 samples and international standards $\left(\mathrm{N}_{2}\right.$ in the air and $\mathrm{CO}_{2}$ in PeeDee belemnite). Gasters were 
181 removed prior to analysis to avoid interference of gut content (Blüthgen, Gebauer \& Fiedler, 182 2003).

183

184 Taxonomic identification

185 Ants were identified with taxonomic revisions, and comparison to identified specimens in 186 collections and AntWeb images (AntWeb, 2016). Updated names were checked with Antcat 187 (Bolton, 2018). Identifications were partially confirmed by taxonomists (see 188 Acknowledgements).

189 In Brazil, ants were identified to genus level with Baccaro et al. (2015) and to species 190 level with: Acanthognathus - Galvis \& Fernández (2009); Acromyrmex - Gonçalves (1961); 191 Cephalotes - De Andrade \& Baroni Urbani (1999); Crematogaster - Longino (2003); 192 Cyphomyrmex - Kempf (1965) and (Snealling \& Longino (1992); Gnamptogenys - Lattke 193 (1995); Hylomyrma - Kempf (1973); Linepithema - Wild (2007); Octostruma - Longino (2013); 194 Odontomachus and Pachycondyla - Fernández (2008); Pheidole - Wilson (2003); Wasmannia 195 Longino \& Fernández (2007). Camponotus and Strumigenys were identified solely by 196 comparison with collections. In Germany, ants were identified to genus and species with Seifert (2007), Seifert \& 198 Schultz (2009), and Radchenko \& Elmes (2010).

All material is stored in the collections of the Ecological Networks research group, 200 Technische Universität Darmstadt, Darmstadt, Germany, and Department of Ecology and 201 Zoology, Federal University of Santa Catarina, Florianópolis, Brazil.

202

203 Data analysis 
As a first step, we compared species' incidences in baits and pitfalls (i.e. number of

205

206

207

208

209

210

211

212

213

214

215

216

217

218

219

220

221

222

223

224

225

sampling points where it was recorded with each method). We assumed incidence in pitfalls to represent abundance in the community, and qualitatively compared it to incidence in baits to check whether common species were underrepresented in baits. To account for different efficiencies between methods, expected incidences were indicated by a line of slope $m=$ $I_{\text {baits }} / I_{\text {pitfalls, }}$ where I is the sum of all incidences for each method (Houadria et al., 2015).

Number of species, replicates and individuals per sample differed between methods, based on sample availability and ant size. In Brazil, we analyzed 24 species for baits, 41 for FAA and 31 for SIA. Method comparisons were performed only with 22 species considered in all three datasets. In Germany, seven species were analyzed with all methods. For a full list of recorded species and respective labels used in plots, see Table S1.

Unless noted otherwise, similarity matrices were based on unweighted Bray-Curtis dissimilarities, and Mantel tests and correlations used Spearman's coefficient (rho). Analyses were run in R 3.4.3 (R Core Team, 2017) and PAST 3.14 (Hammer, Harper \& Ryan, 2001).

For all bait analyses, we used proportion of occurrence on each bait type, relative to total records for each species. Only species with at least 10 records from 5 or more sample points were considered. In Brazil, day and night records were considered as independent to calculate proportions. For FAA, we calculated proportions of each NLFA relative to total composition, and used average proportions for each species. All NLFAs with average proportion $>0.01 \%$ were considered. For SIA, we also used species' averages and analyzed $\delta^{15} \mathrm{~N}$ and $\delta^{13} \mathrm{C}$ separately, using Euclidean distances to build similarity matrices. A special case was Lasius fuliginosus in Germany, which was represented by a single colony that foraged over a large area. Bait records 
226 in different sample points were considered independent, and chemical results represent the

227 average of different samples from that colony.

228 To analyze resource use, we used clustering and network analysis. UPGMA clustering

229 was used for species, to show functional groups based on similar use of resources, and for baits,

230 to show the structure of resource use in each community. Statistical significance of clusters was

231 tested with SIMPROF (Clarke, Somerfield \& Gorley, 2008) using the package "clustsig"

232 (Whitaker \& Christman, 2015). A Mantel test was used to compare similarity matrices of Brazil 233 and Germany.

234 For network analysis, we used quantitative modularity $(Q)$ (Dormann \& Strauss, 2014)

235 and specialization indices for species/resources $\left(d^{\prime}\right)$ and whole networks $\left(H_{2}\right)$ (Blüthgen, Menzel

236 \& Blüthgen, 2006), using the package "bipartite" (Dormann, Fruend \& Gruber, 2017).

237 Modularity shows how compartmentalized a community is, i.e. if there are groups of species that 238 strongly interact with groups of resources. In turn, $d^{\prime}$ indicates whether individual species are 239 specialized in certain resources, or resources that are used by a specialized group of species. $H_{2}{ }^{\prime}$ 240 is an extension of $d^{\prime}$ and shows how specialized the network is overall. $H_{2}{ }^{\prime}=0$ would mean that

241 all species used resources in the same proportions, and $H_{2}{ }^{\prime}=1$ that each species has its exclusive 242 pattern of resource use.

243 Specialization indices were also used to analyze species $\times$ fatty acids contingency tables.

244 In this case, they indicate how exclusively NLFAs are distributed across species (Brückner \& 245 Heethoff, 2017). $H_{2}{ }^{\prime}=0$ would mean that all compounds occur in the same proportion in all 246 species, and $H_{2}^{\prime}=1$ that each species has its exclusive compounds. Correspondingly, relatively 247 high $d^{\prime}$ represents NLFAs that occur more exclusively in certain species, or species with more 248 exclusive proportions of certain NLFAs. Low $d^{\prime}$ means a compound that is widespread among 
249 species, or species with similarly generalized profiles. Additionally, we tested whether the two

250 communities differed in their overall NLFA composition with PERMANOVA, using site as a

251 fixed factor (Anderson, 2001). Homogeneity of multivariate dispersion was tested a priori with

252 PERMDISP (Anderson \& Walsh, 2013). To detect which NLFAs contributed to differences, we 253 used SIMPER (Clarke, 1993). These tests were performed using package "vegan" (Oksanen et 254 al., 2017).

255 To test whether niche breadths and NLFA profile diversity were different between 256 communities at species level, we calculated Shannon diversity indices for each ant species as $H^{\prime}$ $257=\sum p_{i} \ln p_{i}$, where $p_{i}$ is the proportion of each resource $i$ used by the species, or NLFA found in its 258 profile, and compared them with Mann-Whitney tests.

259 To test whether particular NLFAs were related to use of certain resources, we performed 260 Principal Component Analyses (PCA) using baits $\times$ species contingency tables, replacing zeros 261 by small values $(0.000001)$ and using centered log-ratio transformation to deal with the constant262 sum constraint (Brückner \& Heethoff, 2017). PC axes were correlated with NLFAs using 263 function "envfit" from package "vegan". We also compared proportions, amounts (in $\mu \mathrm{g} / \mathrm{mg}$; the 264 amount of fat divided by lean dry weight) and unsaturation indices (UI; the sum of percentages 265 of each unsaturated NLFA multiplied by its number of double bounds) between Brazil and 266 Germany with Mann-Whitney tests. We did this for total fat and the three most abundant NLFAs 267 (C16:0, C18:0 and C18:1n9). To test whether there was a direct relationship between total fat 268 amount and C18:1n9, or total amount and UI, we correlated values for all individual samples of 269 each community (166 in Brazil, 32 in Germany).

270 Finally, to test whether the results yielded by the three methods were correlated, we 271 performed Mantel tests between similarity matrices of species for each method. We also 
272 correlated species' $d^{\prime}$ values for baits and NLFAs, to test whether specialization levels were

273 related.

274 Results

275 Use of resources

276 Most common species were recorded in baits in proportions similar to the expected, given

277 their frequency in the community (Figure S1, Table S1). A few species were underrepresented in 278 baits (e.g. Pachycondyla harpax, Myrmica scabrinodis, Stenamma debile), but, in general, 279 species with few bait records were also rare in pitfalls. Thus we consider that a representative 280 part of the epigeic communities was properly sampled. Despite strong variation in total number 281 of records, the number of species recorded in each bait was similar, with exception of large prey 282 (Table 2). Similarities in resource use were correlated between Brazil and Germany (Figure 1, 284 Mantel test, rho $=0.63, \mathrm{p}=0.03)$. In both communities, large prey was set apart from the other 285 resources, being used less frequently and by fewer species. Seeds and melezitose changed 286 positions between communities. In Germany, all ants used both sugars indiscriminately, while in 287 Brazil several species used more sucrose (e.g. Camponotus zenon, Gnamptogenys striatula, 288 Pachycondyla striata, Odontomachus chelifer, Solenopsis sp.6) and others used more melezitose 289 (e.g. Pheidole aper, Solenopsis sp.8, Wasmannia affinis) (Table 2). Both modularity $\left(Q_{B R}=0.16\right.$, $\left.290 Q_{G E}=0.14\right)$ and network specialization $\left(H_{2}{ }^{\prime} B R=0.13, H_{2^{\prime}}{ }_{G E}=0.12\right)$ were relatively low and 291 similar between sites. Species used resources in different ways and a few were more specialized 292 (see below), but there were no clear links between particular resources and species or groups of 293 species. 
In Brazil, W. auropunctata occupied a highly specialized niche, using only feces baits,

295 which lead to the highest $d^{\prime}$ values for any species and resource. Linepithema iniquum also 296 showed a relatively higher specialization level, due to its preference for dead arthropods and low 297 use of sugars. Pachycondyla striata and O. chelifer used more large prey, dead arthropods and 298 sucrose. Camponotus zenon grouped with them based on use of dead arthropods and sucrose, but 299 avoided large prey. Pheidole aper was the only species to have melezitose as its preferred 300 resource. Other species showed higher redundancy and clustered together, including all 301 Solenopsis and most Pheidole (Figure 1, Table 2).

302 In Germany, only Lasius fuliginosus showed a relatively high specialization level and 303 clustered separately, due to its almost exclusive use of animal resources (living prey and dead 304 arthropods). Other species showed low specialization and dissimilarity (Figure 1, Table 2). Niche breadths were similar between communities (Mann-Whitney, $\mathrm{p}=0.44$ ). Average 306 Shannon index was 1.6 $\pm 0.4 \mathrm{SD}$ in Brazil and 1.7 $\pm 0.1 \mathrm{SD}$ in Germany (Table 2).

Fatty acids

Temperate species contained much higher amounts of total fat than tropical ones (Figure $\mathrm{F}=11.32, \mathrm{p}<0.01)$. This does not change the previous result because, in this case, 313 PERMANOVA becomes overly conservative (Anderson \& Walsh, 2013). species $(\mathrm{SIMPER}$, dissimilarity contribution $=47 \%, \mathrm{p}<0.01$, Figure $2 \& 3$, Tables 3). In Brazil, 316 composition was more balanced, which led to higher proportions of C18:0 (contribution $=21 \%$, 
$317 \mathrm{p}<0.01$ ), although amounts were similar. C16:0 was proportionally the most abundant NLFA in

318 Brazil and the difference from Germany was marginally significant (contribution $=20 \%, \mathrm{p}=$ 319 0.06), although amounts again were higher in temperate species. A few other NLFAs had 320 statistically significant, but very small contributions to the difference (Table S2).

321 Fatty acid compositions were generalized overall, but more homogeneous in Germany 322 because of the general predominance of C18:1n9 $\left(H_{2}{ }^{\prime} B R=0.09, H_{2}{ }^{\prime} G E=0.03\right)$. Accordingly, 323 NLFA profile diversity was higher in tropical species (average Shannon index $=1.5 \pm 0.2$ SD) 324 than temperate ones $(0.9 \pm 0.2 \mathrm{SD})$ (Mann-Whitney, $\mathrm{p}<0.01)$ (Figure 3, Table 3).

325 In samples from Germany, there was no correlation between total amount of fat and 326 percentage of $\mathrm{C} 18: \ln 9$ (rho $=0.19, \mathrm{p}=0.30)$ or unsaturation index (rho $=0.24, \mathrm{p}=0.89$ ). In 327 samples from Brazil, there was weak negative correlation between total fat and both C18:1n9 $328($ rho $=-0.16, p=0.04)$ and unsaturation index $($ rho $=-0.22, p>0.01)$. In Brazil, several fatty acids were related to resource use (Figure 4; see Table S3 for PCA 330 eigenvalues and full Envfit results). Species with higher C18:1n9 also used more dead arthropods 331 (Envfit, $\mathrm{r}^{2}$ of the NLFA with PC axes $=0.32, \mathrm{p}=0.02$ ), while C18:2unk1 (an unidentified 332 NLFA) was related to use of sucrose and large prey $\left(\mathrm{r}^{2}=0.31, \mathrm{p}=0.03\right) . \mathrm{C} 14: 0$ (mystric acid) 333 tended to be higher in species which used more seeds, feces, and small prey $\left(\mathrm{r}^{2}=0.39, \mathrm{p}=0.01\right)$. 334 Notice that the first two Principal Components explained only $60 \%$ of the variance and linear 335 regressions were not strong. In Germany, most variation was along the sugar-protein axis. C18:0 336 and C17:0 (margaric acid) were strongly correlated with PC axes $\left(\mathrm{r}^{2}=0.84, \mathrm{p}=0.05\right.$ and $\mathrm{r}^{2}=$ $3370.78, \mathrm{p}=0.04$, respectively). Both were higher in species that used more sugars, and C17:0 was 338 also related to use of feces, although its relative abundance was very low in all species $(<0.5 \%$, 339 Table 3). 
341 Stable isotopes

342 In Brazil, W. auropunctata presented distinctive signatures for both isotopes. It was the 343 species with highest $\delta^{15} \mathrm{~N}$, while most species ranged from 5.8 to 8.2 , and six showed 344 conspicuously lower signatures. Besides $W$. auropunctata, $\delta^{13} \mathrm{C}$ varied less, ranging from -24.1 345 to -27 (Figure 5, Table 4).

346 In Germany, $\delta^{15} \mathrm{~N}$ was lower overall, ranging from 3.6 (Lasius niger) to -1.1 (Lasius 347 fuliginosus). Species varied little in $\delta^{13} \mathrm{C}$ (from -25.4 to -26.3 ), with values within the range of 348 Brazilian species (Figure 5, Table 4).

349 Isotope signatures were correlated for tropical species (rho $=0.43, \mathrm{p}=0.02$ ). For 350 temperate species, the correlation lacked statistical significance (rho $=-0.46, p=0.3$ ), but their 351 inclusion slightly strengthened the correlation for all species together ( $r h o=0.47, \mathrm{p}<0.01)$.

\section{Dataset comparisons}

In Brazil, similarities in bait use and NLFA profiles were correlated (Table 5). While $355 \delta^{15} \mathrm{~N}$ similarities were correlated with similarities in bait use, but not with NLFAs, the opposite 356 was found for $\delta^{13} \mathrm{C}$. That is, similar use of resources among species was reflected in similar body 357 fat composition, and both were related to their long-term trophic position, albeit in different ways. 358 In Germany, no such correlations were found between datasets (although it was marginally 359 significant for NLFAs and $\left.\delta^{15} \mathrm{~N}\right)$.

360 Exclusiveness $\left(d^{\prime}\right)$ of bait choices and NLFAs profiles were also correlated in Brazil (rho $361=0.51, \mathrm{p}=0.02$ ), suggesting that specialization on resources was reflected in more specific 
362 compositions of fatty acids. No correlation was observed in Germany (rho $=-0.07, p=0.86$ )

363 (Figure 6).

364

365 Discussion

366 Our main findings in this work are: (1) patterns of resource use are similar in both 367 communities, although the role of oligosaccharides is distinct; (2) both communities are similarly 368 generalized in resource use, regardless of species richness; (3) temperate ants present higher 369 amounts of fat and more homogeneous NLFA compositions; (4) composition and specialization 370 in resource use and NLFAs are correlated, and are also related to species' trophic position; (5) 371 some species show specialized behaviors that can be better understood by method 372 complementarity.

373 The hypothesis proposed by MacArthur (1972) suggested that specialization is higher in 374 tropical communities because the environmental stability allows species to adapt to more 375 specialized niches without increasing extinction risk, thus allowing more species to coexist. 376 However, this idea was put in question by recent studies, where the latitude-richness377 specialization link was not confirmed, or an inverse trend was found (Schleuning et al., 2012; 378 Morris et al., 2014; Frank et al., 2018). Our work is not an explicit test of this hypothesis, but 379 several results agree with the view that specialization does not necessarily increase with higher 380 richness towards the tropics: despite the different number of species, network metrics of resource 381 use and niche breadths were similarly generalized in both communities; fatty acid compositions 382 were also highly generalized, although in this case in different level, possibly due to other factors 383 (see discussion on Fatty Acids below); cluster analysis of resource use showed similar patterns 
384 between communities; and both species clusters and stable isotopes indicated strong overlap 385 inside each community.

386 The bait protocol we applied is efficient to assess niches of generalists, and specialized 387 species were seldom recorded. Nevertheless, these generalists represent the majority of the 388 communities (as highlighted by our pitfall data), and one might expect more diversified niches to 389 allow coexistence, but that was not the case. The differences we observed might still play a role 390 in coexistence of some species, particularly when they share other traits, such as $O$. chelifer and 391 Pachycondyla striata. Both are large, solitary foraging Ponerinae species, very common on the 392 ground of the Atlantic forest, but O. chelifer is more predatory and Pachycondyla striata more 393 scavenging (Rosumek, 2017). Coexistence is result of a complex interplay of habitat structure, 394 interspecific interactions and species traits, and no single factor governs ant community 395 organization (Cerdá, Arnan \& Retana, 2013). Trophic niche alone does not explain coexistence 396 of the common species in these two communities, but likely is one of the many factors 397 structuring them.

398

399 Use of resources

400 Resource use in Brazil was discussed in detail in Rosumek (2017), as well as the 401 literature review on trophic niche of our identified tropical species. Large prey was the less used 402 resource, because size and mobility of the prey limits which species are able to overcome them. 403 Small prey and feces were also relatively less used, the first because also is relatively challenging 404 to acquire, and the second probably due to smaller nutritional value. On the other hand, the other 405 resources are nutritive and relatively easy to gather, particularly dead arthropods, which was by 
406 far the most used resource. Considering the similarity in resource use patterns, most remarks in

407 that work apply to Germany as well. The two main differences we found are discussed below.

408 The role of insect-synthesized oligosaccharides seems to be distinct between temperate

409 and tropical communities. In Brazil, the aversion to melezitose showed by some species could 410 represent a physiological constraint, since tolerance to oligosaccharides differs among ant 411 species (Rosumek, 2017). For ants without physiological constraints, melezitose use might be 412 opportunistic and does not necessarily mean that they interact with sap-sucking insects. However, 413 honeydew is the only reliable source of oligosaccharides in nature, so the few species that 414 preferred this sugar may engage in such interactions (particularly Pheidole aper). In Germany, 415 on the other hand, all species used both sugars similarly. The two Myrmica, Lasius and Formica 416 fusca are known to interact with sap-sucking insects, and Temnothorax nylanderi uses honeydew 417 opportunistically when droplets fall on the ground (Seifert, 2007).

418 Seeds were other resource used differently, but this probably is consequence of our 419 methodological choice of seeds with elaiosomes in Germany. Elaiosomes are thought to mimic 420 animal prey and attract predators and scavengers (Hughes, Westoby \& Jurado, 1994), not only 421 granivores. Effectively, elaiosomes of Chelidonium majus are attractive to a wide range of ants

422 (Reifenrath, Becker \& Poethke, 2012). However, seeds were more extensively used in Brazil. A 423 higher diversity of shape and sizes of seeds was offered there, which allowed more ants to use 424 them.

425

426 Fatty acids

427 Fatty acid compositions were generalized, but differed between communities. In 428 Germany, C18:1n9 plays a prominent role, making up for more than $70 \%$ of the NLFAs stored 
429 by ants. The amounts of fat also differed remarkably: in average, temperate ants stored over five

430 times more fat. Similarly high amounts of total fat and percentages of C18:1n9 were observed in

431 laboratory colonies of $F$. fusca and M. rubra (Rosumek et al., 2017), which suggest that it might

432 be a general trend for temperate species. In Brazil, NLFA abundance at community level was

433 more balanced between $\mathrm{C} 16: 0, \mathrm{C} 18: 0$ and $\mathrm{C} 18: 1 \mathrm{n} 9$. Both amounts and proportions of C18:1n9

434 were variable among species.

435 Organisms can actively change their fatty acid composition in response to environmental

436 factors and physiological needs (Stanley-Samuelson et al., 1988). Temperature and balance

437 between saturated and unsaturated NLFAs are important, because the fat body should present a

438 certain fluidity that allows enzymes to access stored nutrients (Ruess \& Chamberlain, 2010).

$439 \mathrm{C} 18: \ln 9$ seems to be the only unsaturated fatty acid that ants are able to synthesize by

440 themselves in large amounts (Rosumek et al., 2017). However, there was no positive correlation

441 between amount of fat and C18:1n9 or unsaturation index of samples, which would be expected

442 if $\mathrm{C} 18: \ln 9$ synthesis was a direct mechanism of individuals to balance saturation:unsaturation

443 ratios (the weak negative correlation in Brazil also does not fit this hypothesis).

444 Therefore, we suggest that differences in $\mathrm{C} 18: \ln 9$ percentages and total amounts could

445 be consequence of two distinct environmental factors. Under lower temperatures, higher 446 proportion of unsaturated fatty acids is needed to maintain lipid fluidity (Jagdale \& Gordon, 447 1997). Thus, temperate species might be adapted to synthesize and store more $\mathrm{C} 18: \ln 9$ to 448 withstand the cold seasons. If this hypothesis were correct, the ants would maintain this high 449 proportion throughout the year, since we collected in summer. In turn, high amount of fat could 450 be a direct consequence of the marked seasonality in temperate regions. These species might be 
451 adapted to quickly acquire and accumulate energy reserves during the short warm season, while

452 there is less pressure for this in regions where resources are available throughout the year.

453

We observed relationships between certain NLFAs and resources, although overall they

454 were not strong and not necessarily a result of direct trophic transfer. C18:1n9 was related to use

455 of dead arthropods in Brazil. This NLFA is considered a "necromone", a chemical clue for

456 recognition of corpses by ants and other insects (Sun \& Zhou, 2013), so it presumably increases

457 in dead arthropods. However, only polyunsaturated fatty acids can be degraded to form C18:1n9

458 during decomposition, and C18:1n9 itself turns into C18:0 (Dent, Forbes \& Stuart, 2004). Thus,

459 for high $\mathrm{C} 18: \ln 9$ to be a direct result of scavenging, prey items should previously possess high

460 levels of unsaturation. This might be an indirect effect as well: scavenger ants might be better at

461 tracking and retrieving food items that are naturally rich in C18:1n9. No correlation was found in

462 Germany, which could also be related to the special role of this NLFA in temperate species: its

463 predominance due to environmental factors may override its dietary signal.

464

C18:2n6 occurs independently of diet only in very small amounts, and it is a potential

465 biomarker (Rosumek et al., 2017). The differences we observed among species are direct result

466 of diet. Its occurrence was more widespread in Brazil, but we observed no clear correlation with

467 specific resources. C18:2n6 is found in elaiosomes, seeds and other arthropods in different

468 amounts (Thompson, 1973; Hughes, Westoby \& Jurado, 1994). Since it can come from different

469 sources, C18:2n6 cannot be straightforwardly used as a biomarker for specific diets, but depends

470 on a deeper analysis of the resources actually available in the habitat.

471 The biological significance of the correlations of NLFAs and resources in Germany is

472 difficult to grasp. C18:0 does not appear to be preferably synthesized from carbohydrates,

473 compared to C16:0 and C18:1n9 (Rosumek et al., 2017). Adding to the fact that such correlation 
474 was not found in Brazil, this might not represent a physiological link between sugar consumption

475 and C18:0 synthesis. With low number of species in Germany, even strong correlations might be

476 product of species-specific factors other than diet. The same might be said for C17:0, a fatty acid

477 that occurs in very low amounts in several vegetable oils (Beare-Rogers, Dieffenbacher \& Holm, 478 2001).

479

Interestingly, we did not observe any $18: 3 n 3$ or 18:3n6 ( $\alpha$ - and $\gamma$-linolenic acids). Ants 480 are not able to synthesize them, and they are assimilated through direct trophic transfer 481 (Rosumek et al., 2017). In the studied communities, these fatty acids seem to be completely 482 absent from food sources used by ants. This is an unexpected result, since their occurrence is 483 well documented in elaiosomes and a wide range of insect groups that might serve as prey 484 (Thompson, 1973; Hughes, Westoby \& Jurado, 1994).

The use of fatty acids as biomarkers to track food sources is one of the greatest potentials 486 of this method. However, it might be more suitable to detritivore systems, where the biomarkers 487 are distinctive membrane phospholipids from microorganisms that decompose specific resources, 488 and that end up stored in the fat reserves of the consumers (Ruess \& Chamberlain, 2010). The 489 NLFA profiles we observed are generalized, and the most relevant fatty acids could represent 490 distinct sources and/or be synthesized de novo in large amounts. The biomarker approach might 491 not be suitable at community level for ground ants, contrary to NLFA profiles (see Method 492 Comparison below). However, it still might be useful to unveil species-specific interactions, or in 493 contexts with less potential sources that can be better tracked (e.g. leaf-litter or subterranean 494 species).

495

496 Stable isotopes 
498 another) varies among taxonomic groups and according to other physiological factors 499 (McCutchan et al., 2003). "Typical" values of ca. 3\% for $\delta^{15} \mathrm{~N}$ and $1 \%$ for $\delta^{13} \mathrm{C}$ were 500 experimentally observed in one ant species (Feldhaar, Gebauer \& Blüthgen, 2010). Establishing 501 discrete trophic levels is unrealistic in most food webs, particularly for omnivores such as ants 502 (Polis \& Strong, 1996), but species within the range of one trophic shift are more likely to use 503 resources in a similar way. $\delta^{15} \mathrm{~N}$ ranges of ca. $9 \%$ were observed for ant communities in other 504 tropical forests, representing three trophic shifts (Davidson et al., 2003; Bihn, Gebauer \& Brandl, 505 2010). This is similar to our range of $8.9 \%$ but, discounting $W$. auropunctata, the remaining 506 range of $6.1 \%$ is more similar to what was observed in an Australian forest (7.1\%o; Blüthgen, 507 Gebauer \& Fiedler, 2003). In Germany, only Lasius fuliginosus presented a distinct signature. In 508 both communities, most species fell within the range of one trophic shift.

$\delta^{13} \mathrm{C}$ showed smaller, but meaningful, variations that were correlated to $\delta^{15} \mathrm{~N} . \delta^{13} \mathrm{C}$ is less 510 applied to infer trophic levels, as it is more sensitive to sample preservation method and diet 511 composition (Tillberg et al., 2006; Heethoff \& Scheu, 2016). An average change of 0.61\%o was 512 observed in samples stored in ethanol by Tillberg et al. (2006). However, we observed 513 correlations (including with NLFAs - see below) despite this eventual change, and it would not 514 affect the similarity among species and between communities. Primary consumers using distinct 515 plant sources may present differences of up to $20 \%$, and this will influence the signature of 516 secondary consumers (O’Leary, 1988; Gannes, Del Rio \& Koch, 1998). However, in our case, 517 only $W$. auropunctata presented such distinct value.

518 Again, both isotopes suggest that the core of these communities is composed by 519 generalists that broadly use the same resources. Since we did not establish baselines, lower 
520 values in Germany do not necessarily mean lower trophic levels in this community. Isotope

521 signatures for the same species are highly variable among sites in Europe (Fiedler et al., 2007),

522 and this variation can be the result of either different isotope baselines or actual changes in

523 species' ecological roles.

524 Low $\delta^{15} \mathrm{~N}$ suggest that a species obtain most of their nitrogen from basal trophic levels,

525 mainly plant sources (Blüthgen, Gebauer \& Fiedler, 2003; Davidson et al., 2003). This fits the

526 six species with lowest $\delta^{15} \mathrm{~N}$ in Brazil. Two were fungus-growing ants (Acromyrmex aspersus,

527 Trachymyrmex sp.1), which use mostly plant material to grow its fungus. The others were

528 species that forage frequently on vegetation, besides the ground (Camponotus lespesii,

529 Camponotus zenon, Crematogaster nigropilosa, Linepithema iniquum). Arboreal species that

530 heavily rely on nectar or honeydew usually present low $\delta^{15} \mathrm{~N}$, which may be the case for these

531 species. Linepithema represents well this trend: the two mainly ground-nesting species,

532 Linepithema micans and Linepithema pulex, presented higher signatures than the plant-nesting

533 Linepithema iniquum (Wild, 2007).

534

535 Community patterns and method comparison

536 The correlations we observed between methods are interesting from both the

537 methodological and the biological perspective. From a methodological viewpoint, for terrestrial

538 animals, this is the first time an empirical relationship is shown between patterns of resource use

539 and composition of stored fat in natural conditions, and that both relate to their long-term trophic

540 position. Although differences between species were small, these relationships were robust

541 enough to be detected by different methods. From a biological viewpoint, it highlights several

542 physiological mechanisms involved in such relationships. We will discuss in the following some 
543 of these mechanisms, as well as caveats that are often cited for these methods. They probably

544 still influence our results and correlations, but did not completely override the patterns.

545 A commonly cited caveat for using baits is that ants could be attracted to the most limited

546 resources, instead of the ones they use more often. Evidence for this comes mainly from

547 nitrogen-deprived arboreal ants (Kaspari \& Yanoviak, 2001), and some cases are discussed

548 below (see Method Complementarity). However, this effect might be less pronounced in epigeic

549 species, and our results suggest that there is convergence between bait attendance, and medium550 and long-term use of resources.

551 Diet may significantly change NLFA composition in a few weeks (Rosumek et al., 2017)

552 and persist for a similar time (Haubert, Pollierer \& Scheu, 2011). Therefore, the "snapshot" of

553 resource use we observed with baits should represent at least the seasonal preferences of the 554 species. A seasonal study on NLFA compositional changes can bring valuable information on 555 resource use changes, or if these compositions are stable throughout the year.

556 Adult ants are thought to feed mostly on liquid foods, due to the morphology of the 557 proventriculus, which prevents solid particles to pass from the crop to the midgut (Eisner \& 558 Happ, 1962). Larvae are able to process solids and possess a more diversified suit of enzymes, 559 and are sometimes called the "digestive caste" of the colony (Hölldobler \& Wilson, 1990; Erthal, 560 Peres Silva \& Ian Samuels, 2007). Trophallaxis is an important mechanism of food sharing 561 between workers and larvae. Our results suggest that the trophic signal of NLFAs is not lost in 562 this processes, and that might be true even for solid items such as arthropods or seeds. However, 563 the similarities could be as well the result of direct digestion and assimilation of liquid sources 564 (sugars, hemolymph). 
We also found correlations with stable isotopes. They were weaker than between baits

566 and NLFAs, and different for each isotope. For $\delta^{15} \mathrm{~N}$, it shows that patterns of resource use are

567 more correlated with trophic level. Protein amino acids must be obtained from diet or

568 synthesized from other nitrogenated compounds, so the signal relative to nitrogen sources should

569 be more preserved. This also fits to the idea that $\delta^{15} \mathrm{~N}$ reflects larval diet, because it is in this

570 stage that ants grow and build most of their biomass (Blüthgen \& Feldhaar, 2010). On the other

571 hand, it makes sense that the signal relative to carbon sources is related to NLFA composition.

572 We should note that we removed the gaster of the ants used in SIA, so we observed only the

573 signal of carbon incorporated in the other body parts. This is related to dietary carbon, but a

574 stronger signal could be expected if the fat body is included.

575 The low source-specificity of stable isotope signatures might also lead to relatively weak 576 correlations. Pachycondyla striata and $O$. chelifer and $P a$. striata had the same $\delta^{15} \mathrm{~N}$ despite their

577 different preferences. Other species that appear to be mostly scavengers had similar or higher

$578 \delta^{15} \mathrm{~N}$ than those two "predators", such as Linepithema micans, Pheidole sarcina, Pheidole

579 lucretii and Pheidole sp.4.

580 In Germany, no correlation was observed between methods. This is probably a 581 consequence of the low number of species available in the community The relationships found in 582 Brazil might be valid for other communities, although ecological context and physiology might 583 change their significance or strength.

585 Species niches and method complementarity

586 Niche differences were correlated at community level, but the use of different techniques 587 allows better understanding of species' niches. Method complementarity is particularly important 
588 if one is interested in the functional role of individual species, not only in overall patterns. Some 589 cases are described below.

590 In Brazil, W. auropunctata was distinct from the remaining community, both in resource 591 use and isotopic signature (unfortunately, no NLFA samples were obtained for this species). 592 Strong preference for feces is a novel behavior for this species, known to invade and dominate 593 disturbed habitats, but less dominant inside forests (Rosumek, 2017). Its isotopic signature 594 confirms that they have a highly differentiated diet, and could be direct result of a feces-rich diet. 595 In herbivorous mammals, feces are usually enriched in $\delta^{15} \mathrm{~N}$ relative to diet (Sponheimer et al., 596 2003; Hwang, Millar \& Longstaffe, 2007). The proposed mechanism of ${ }^{15} \mathrm{~N}$ enrichment along 597 trophic levels states that this happens due to preferential excretion of ${ }^{14} \mathrm{~N}$, and it is assumed that 598 most nitrogen is excreted in the urine, which is depleted in ${ }^{15} \mathrm{~N}$ (Peterson \& Fry 1987, Gannes et 599 al. 1997, but see Sponheimer et al. 2003). However, ${ }^{15} \mathrm{~N}$-enriched feces were also observed in 600 uricotelic organisms, such as birds and locusts (Webb, Hedges \& Simpson, 1998; Bird et al., 601 2008). Thus, high $\delta^{15} \mathrm{~N}$ is consistent with a diet based on ${ }^{15} \mathrm{~N}$-enriched feces from other 602 consumers. The relationship with the $\delta^{13} \mathrm{C}$ signature is less clear, but it also suggests high 603 specialization.

This behavior might be a local adaptation, but also could indicate that $W$. auropunctata 605 shifts to less disputed resources inside native forests (although the exact resources used may be 606 context-dependent). In Davidson (2005), Wasmannia species (including W. auropunctata) 607 presented relatively high $\delta^{15} \mathrm{~N}$ and were considered highly carnivorous. However, our result 608 shows that high $\delta^{15} \mathrm{~N}$ should not be taken from granted to represent high-level consumers. It 609 might be a solid generalization for communities, but other trophic pathways may lead to such 610 signatures. Due to their lack of specificity, isotope signatures should be combined with field 
611 observations to provide reliable information at species level. As another example, the second

612 highest $\delta^{15} \mathrm{~N}$ in our work was observed in Pheidole sp.7, a species that used mainly seeds and

613 was seldom recorded in animal (or feces) baits.

614 Another example where results seem to be contradictory is Lasius fuliginosus, which

615 showed strong preference for animal baits, but low $\delta^{15} \mathrm{~N}$. In this case, the natural history of the

616 species is well known, and it strongly interacts with aphids, particularly the giant oak aphid

617 Stomaphis quercus (Seifert, 2007). This suggests that this aphid's honeydew is not enriched in

$618{ }^{15} \mathrm{~N}$ and has a composition similar to the plants on which they feed. The honeydew supply should

619 be abundant, since ants basically ignored sugar baits, but also relatively poor in nitrogen, which

620 makes Lasius fuliginosus use animal sources whenever possible. A similar pattern may apply to

621 Linepithema iniquum in Brazil, which also combined low $\delta^{15} \mathrm{~N}$ with preference for animal baits.

622 This species is also known to use extra-floral nectaries and honeydew (Rosumek, 2017), but does

623 not have such strong and specific interactions as its temperate counterpart.

624

\section{Conclusions}

626 In this work, we investigated two communities with three distinct methods, and provided

627 information on community patterns of resource use and species' trophic niches. Our results agree

628 with the view that ant communities are mostly composed by generalist species that share similar

629 resources, and suggest that such patterns do not differ between tropical and temperate

630 communities. Although high richness may lead to more specialists in the tropics, the generalist

631 core of the community should be maintained by a combination of several factors.

632 Overall, we observed that the three methods corresponded in their characterization of the 633 communities, but their combination provided a more comprehensive picture of resource use. 
634 However, the time and costs demanded should limit the broad application of this framework, and

635 some techniques are more suitable to answer particular questions. We gave special focus on fatty

636 acid analysis in this work, because it was the first time this method was applied to study ant

637 ecology in the field. Considering that NLFA profiles provide a more time-representative

638 snapshot than baits, and are more specific than stable isotopes, we suggest FAA as a powerful

639 tool to study trophic niche relationships in species-rich ant communities. It allows the researcher

640 to obtain quantitative data related to diet with relatively short fieldwork time, or from systems

641 where direct observation is limited, and then use it to infer niche breadths, similarities and

642 overlap. However, their use as biomarkers has yet to be developed, and seems to be limited for

643 epigeic ant communities. Combining NLFA compositions with field observations is strongly

644 recommended, if the researcher is interested in source-specificity. Finally, stable isotopes

645 (particularly $\delta^{15} \mathrm{~N}$ ) might be added as a long-term representation of trophic position, which can

646 corroborate or complement other results.

647

648 Acknowledgements

649 Cristian Klunk, Frederico Rottgers Marcineiro, Larissa Zanette da Silva, Lukas Kauling

650 and Felix Schilcher for assistance in fieldwork and sample sorting. Anna Ruppenthal for

651 assistance in fieldwork and FAA of German ants. Christine Tiroch for technical assistance in

652 EA-IRMS. Rodrigo Machado Feitosa, Alexandre Casadei Ferreira, Thiago Sanches Ranzani da

653 Silva and Francisco Hita Garcia for taxonomic assistance. Two anonymous reviewers for

654 valuable comments and suggestions.

655

656 References 
657 Albrecht M, Gotelli NJ. 2001. Spatial and temporal niche partitioning in grassland ants.

658 Oecologia 126:134-141 DOI 10.1007/s004420000494.

659 Andersen AN. 2000. A global ecology of rainforest ants: functional groups in relation to

660 environmental stress and disturbance. In: Agosti D, Majer JD, Alonso LE, Schultz TR, eds.

661 Ants: standard methods for measuring and monitoring biodiversity. Washington, DC:

662 Smithsonian Institution Press, 25-34.

663 Anderson MJ. 2001. A new method for non-parametric multivariate analysis of variance. Austral

664 Ecology 26:32-46 DOI 10.1111/j.1442-9993.2001.01070.pp.x.

665 Anderson MJ, Walsh DCI. 2013. PERMANOVA, ANOSIM, and the Mantel test in the face of

666 heterogeneous dispersions: what null hypothesis are you testing? Ecological Monographs

$667 \quad 83: 557-574$ DOI 10.1890/12-2010.1.

668 De Andrade ML, Baroni Urbani C. 1999. Diversity and adaptation in the ant genus Cephalotes,

669 past and present. Stuttgarter Beiträge zur Naturkunde. Serie B (Geologie und

670 Paläontologie) 271:1-889.

671 AntWeb. 2016. AntWeb. Available at http://www.antweb.org/(accessed 15 March 2016).

672 Beare-Rogers JL, Dieffenbacher A, Holm JV. 2001. Lexicon of lipid nutrition (IUPAC Technical

673 Report). Pure and Applied Chemistry 73:685-744 DOI 10.1351/pac200173040685.

674 Bestelmeyer BT, Agosti D, Alonso LE, Brandão CRF, Brown WL, Delabie JHC, Silvestre R.

675 2000. Field techniques for the study of ground-dwelling ants. In: Agosti D, Majer JD,

676 Alonso LE, Schultz TR, eds. Ants: standard methods for measuring and monitoring

677 biodiversity. Washington, DC: Smithsonian Institution Press, 122-144.

678 Bidartondo MI, Burghardt B, Gebauer G, Bruns TD, Read DJ. 2004. Changing partners in the

679 dark: isotopic and molecular evidence of ectomycorrhizal liaisons between forest orchids 
680

681

682

683

684

685

686

687

688

689

690

691

692

693

694

695

696

697

698

699

700

701

702

and trees. Proceedings of the Royal Society B: Biological Sciences 271:1799-1806 DOI 10.1098/rspb.2004.2807.

Bihn JH, Gebauer G, Brandl R. 2010. Loss of functional diversity of ant assemblages in secondary tropical forests. Ecology 91:782-792 DOI 10.1890/08-1276.1.

Bird MI, Tait E, Wurster CM, Furness RW. 2008. Stable carbon and nitrogen isotope analysis of avian uric acid. Rapid Communications in Mass Spectrometry 22:3393-3400 DOI 10.1002/rcm.3739.

Birkhofer K, Bylund H, Dalin P, Ferlian O, Gagic V, Hambäck PA, Klapwijk M, Mestre L, Roubinet E, Schroeder M, Stenberg JA, Porcel M, Björkman C, Jonsson M. 2017. Methods to identify the prey of invertebrate predators in terrestrial field studies. Ecology and Evolution 7:1942-1953 DOI 10.1002/ece3.2791.

Blüthgen N, Feldhaar H. 2010. Food and shelter: How resources influence ant ecology. In: Lach L, Parr CL, Abbott KL, eds. Ant Ecology. Oxford: Oxford University Press, 115-136.

Blüthgen N, Gebauer G, Fiedler K. 2003. Disentangling a rainforest food web using stable isotopes: dietary diversity in a species-rich ant community. Oecologia 137:426-435 DOI 10.1007/s00442-003-1347-8.

Blüthgen N, Menzel F, Blüthgen N. 2006. Measuring specialization in species interaction networks. BMC Ecology 6:9 DOI 10.1186/1472-6785-6-9.

Bolton B. 2018. An online catalog of the ants of the world. Available at http://antcat.org/ (accessed 4 June 4 2018).

Brückner A, Heethoff M. 2017. A chemo-ecologists' practical guide to compositional data analysis. Chemoecology 27:33-46 DOI 10.1007/s00049-016-0227-8.

Budge SM, Iverson SJ, Koopman HN. 2006. Studying trophic ecology in marine ecosystems 
703

704

705

706

707

708

709

710

711

712

713

714

715

716

717

718

719

720

721

722

723

724

725

using fatty acids: a primer on analysis and interpretation. Marine Mammal Science 22:759_ 801 DOI 10.1111/j.1748-7692.2006.00079.x.

Cerdá X, Retana J, Cros S. 1997. Thermal disruption of transitive hierarquies in Mediterranean ant communities. Journal of Animal Ecology 66:363-374 DOI 10.2307/5982.

Cerdá X, Arnan X, Retana J. 2013. Is competition a significant hallmark of ant (Hymenoptera: Formicidae) ecology? Myrmecological News 18:131-147.

Clarke KR. 1993. Non-parametric multivariate analyses of changes in community structure. Australian Journal of Ecology 18:117-143 DOI 10.1111/j.1442-9993.1993.tb00438.x.

Clarke KR, Somerfield PJ, Gorley RN. 2008. Testing of null hypotheses in exploratory community analyses: similarity profiles and biota-environment linkage. Journal of Experimental Marine Biology and Ecology 366:56-69 DOI 10.1016/J.JEMBE.2008.07.009.

Davidson DW. 2005. Ecological stoichiometry of ants in a New World rain forest. Oecologia 142:221-231 DOI 10.1007/s00442-004-1722-0.

Davidson DW, Cook SC, Snelling RR, Chua TH. 2003. Explaining the abundance of ants in lowland tropical rainforest canopies. Science 300:969-972 DOI 10.1126/science.1082074.

Dent BB, Forbes SL, Stuart BH. 2004. Review of human decomposition processes in soil. Environmental Geology 45:576-585 DOI 10.1007/s00254-003-0913-z.

Dormann CF, Fruend J, Gruber B. 2017. bipartite: visualising bipartite networks and calculating some (ecological) indices. v.2.08. Available at https://cran.r-project.org/package=bipartite.

Dormann CF, Strauss R. 2014. A method for detecting modules in quantitative bipartite networks. Methods in Ecology and Evolution 5:90-98 DOI 10.1111/2041-210X.12139.

Eisner T, Happ GM. 1962. The Infrabuccal pocket of a Formicine ant: a social filtration device. Psyche: A Journal of Entomology 69:107-116 DOI 10.1155/1962/25068. 
726 Erthal M, Peres Silva C, Ian Samuels R. 2007. Digestive enzymes in larvae of the leaf cutting ant, 727 Acromyrmex subterraneus (Hymenoptera: Formicidae: Attini). Journal of Insect Physiology $728 \quad 53: 1101-1111$ DOI 10.1016/J.JINSPHYS.2007.06.014.

729 Feldhaar H, Gebauer G, Blüthgen N. 2010. Stable isotopes: past and future in exposing secrets of 730 ant nutrition (Hymenoptera: Formicidae). Myrmecological News 13:3-13.

731 Fernández F. 2008. Subfamilia Ponerinae s. str. In: Jiménez E, Fernández F, Arias TM, Lozano732 Zambrano FH, eds. Sistemática, biogeografía y conservación de las hormigas cazadoras de 733 Colombia. Bogotá: Instituto de Investigación de Recursos Biológicos Alexander von $734 \quad$ Humboldt, 123-218.

735 Fiedler K, Kuhlmann F, Schlick-Steiner BC, Steiner FM, Gebauer G. 2007. Stable N-isotope 736 signatures of central European ants - assessing positions in a trophic gradient. Insectes Sociaux 54:393-402 DOI 10.1007/s00040-007-0959-0.

738 Frank K, Krell F-T, Slade EM, Raine EH, Chiew LY, Schmitt T, Vairappan CS, Walter P, 739 Blüthgen N. 2018. Global dung webs: high trophic generalism of dung beetles along the 740 latitudinal diversity gradient. Ecology Letters 21:1229-1236. DOI: 10.1111/ele.13095.

741 Galvis JP, Fernández F. 2009. Ants of Colombia X. Acanthognathus with the description of a 742 new species (Hymenoptera: Formicidae). Revista Colombiana de Entomologia 35:245-249.

743 Gannes LZ, Del Rio CM, Koch P. 1998. Natural abundance variations in stable isotopes and 744 their potential uses in animal physiological ecology. Comparative Biochemistry and 745 Physiology 119A:725-737 DOI 10.1016/S1095-6433(98)01016-2.

746 Gonçalves CR. 1961. O gênero Acromyrmex no Brasil (Hym. Formicidae). Studia Entomologica $747 \quad 4: 113-180$.

748 Greenslade PJM. 1973. Sampling ants with pitfall traps: diggin-in effects. Insectes Sociaux 
750 Hammer Ø, Harper DAT, Ryan PD. 2001. PAST: Paleontological statistics software package for 751 education and data analysis. Palaeontologia Electronica 4:1-9.

752 Haubert D, Birkhofer K, Fließbach A, Gehre M, Scheu S, Ruess L. 2009. Trophic structure and 753 major trophic links in conventional versus organic farming systems as indicated by carbon 754 stable isotope ratios of fatty acids. Oikos $118: 1579-1589$ DOI 10.1111/j.1600755 0706.2009.17587.x.

756

757

758

759

760

761

762

763

764

765

766

767

768

769

770

771

Haubert D, Pollierer MM, Scheu S. 2011. Fatty acid patterns as biomarker for trophic interactions: changes after dietary switch and starvation. Soil Biology and Biochemistry 43:490-494 DOI 10.1016/j.soilbio.2010.10.008.

Heethoff M, Scheu S. 2016. Reliability of isotopic fractionation $(\Delta 15 \mathrm{~N}, \Delta 13 \mathrm{C})$ for the delimitation of trophic levels of oribatid mites: diet strongly affects $\Delta 13 \mathrm{C}$ but not $\Delta 15 \mathrm{~N}$. Soil Biology and Biochemistry 101:124-129 DOI 10.1016/j.soilbio.2016.07.013.

Hölldobler B, Wilson EO. 1990. The Ants. Massachusetts: Harvard University Press.

Houadria M, Salas-Lopez A, Orivel J, Blüthgen N, Menzel F. 2015. Dietary and temporal niche differentiation in tropical ants — can they explain local ant coexistence? Biotropica 47:208217 DOI 10.1111/btp.12184.

Hughes L, Westoby M, Jurado E. 1994. Convergence of elaiosomes and insect prey: evidence from ant foraging behaviour and fatty acid composition. Functional Ecology 8:358-365.

Hwang YT, Millar JS, Longstaffe FJ. 2007. Do $\delta 15 \mathrm{~N}$ and $\delta 13 \mathrm{C}$ values of feces reflect the isotopic composition of diets in small mammals? Canadian Journal of Zoology 85:388-396 DOI 10.1139/Z07-019.

Hyodo F. 2015. Use of stable carbon and nitrogen isotopes in insect trophic ecology. 
773 Jagdale GB, Gordon R. 1997. Effect of temperature on the composition of fatty acids in total

774 lipids and phospholipids of entomopathogenic nematodes. Journal of Thermal Biology

775 22:245-251 DOI 10.1016/S0306-4565(97)00019-3.

776 Kaspari M. 2000. A primer on ant ecology. In: Agosti D, Majer, JD, Alonso, LE, Schultz, TR,

777 eds. Ants: standard methods for measuring and monitoring biodiversity. Washington:

778 Smithsonian Institution Press, 9-24.

779 Kaspari M, Yanoviak SP. 2001. Bait use in tropical litter and canopy ants-evidence of

780 differences in nutrient limitation. Biotropica 33:207-211 DOI 10.1646/0006-

781 3606(2001)033[0207:BUITLA]2.0.CO;2.

782 Kempf WW. 1965. A revision of the neotropical fungus-growing ants of the genus

783 Cyphomyrmex Mayr. Part II: Group of rimosus (Spinola) (Hym. Formicidae). Studia

$784 \quad$ Entomologica 8:161-200.

785 Kempf WW. 1973. A revision of the neotropical myrmicine ant genus Hylomyrma Forel

786 (Hymenoptera: Formicidae). Studia Entomologica 16:225-260.

787 Krebs CJ. 1999. Ecological methodology. Menlo Park, Calif: Benjamin/Cummings.

788 Lanan M. 2014. Spatiotemporal resource distribution and foraging strategies of ants

789 (Hymenoptera: Formicidae). Myrmecological News 20:53-70.

790 Lattke JE. 1995. Revision of the ant genus Gnamptogenys in the New World (Hymenoptera:

$791 \quad$ Formicidae). Journal of Hymenoptera Research 4:137-193.

792 Longino JT. 2003. The Crematogaster (Hymenoptera, Formicidae, Myrmicinae) of Costa Rica.

793 Zootaxa 151:1-150 DOI 10.11646/zootaxa.151.1.1.

794 Longino JT. 2013. A revision of the ant genus Octostruma Forel 1912 (Hymenoptera, 
Formicidae). Zootaxa 3699:1-61 DOI 10.11646/zootaxa.3699.1.1.

796 Longino JT, Fernández F. 2007. Taxonomic review of the genus Wasmannia. Memoirs of the 797 American Entomological Institute 80:271-289.

798 Lopes BC. 2007. Ecologia do forrageio por Cyphomyrmex morschi Emery (Hymenoptera, 799 Formicidae) em vegetação de restinga no Sul do Brasil. Rev Brasil Zool 24:52-56 DOI $800 \quad 10.1590 / \mathrm{S} 0101-81752007000100006$.

801 MacArthur RH. 1972. Geographical ecology: patterns in the distribution of species. Princeton: 802 Princeton University Press.

803 Malcicka M, Visser B, Ellers J. 2018. An evolutionary perspective on linoleic acid synthesis in 804 animals. Evolutionary Biology 45:15-26. DOI: 10.1007/s11692-017-9436-5.

805 McCutchan JH, Lewis WM, Kendall C, McGrath CC. 2003. Variation in trophic shift for stable 806 isotope ratios of carbon, nitrogen, and sulfur. Oikos 102:378-390 DOI 10.1034/j.1600$807 \quad$ 0706.2003.12098.x.

808 Medeiros FNS, Oliveira PS. 2009. Season-dependent foraging patterns case study of a 809 neotropical forest-dwelling ant (Pachycondyla striata; Ponerinae). In: Jarau S, Hrncir M,

812 Morris RJ, Gripenberg S, Lewis OT, Roslin T. 2014. Antagonistic interaction networks are 813 structured independently of latitude and host guild. Ecology Letters 17:340-349 DOI $814 \quad 10.1111 /$ ele.12235.

815 Ngosong C, Raupp J, Scheu S, Ruess L. 2009. Low importance for a fungal based food web in 816 arable soils under mineral and organic fertilization indicated by Collembola grazers. Soil 817 Biology and Biochemistry 41:2308-2317 DOI 10.1016/j.soilbio.2009.08.015. 
818 O'Leary MH. 1988. Carbon isotopes in photosynthesis. BioScience 38:328-336 DOI

$819 \quad 10.2307 / 1310735$

820 Oksanen J, Blanchet FG, Friendly M, Kindt R, Legendre P, McGlinn D, Minchin PR, O’Hara

821 RB, Simpson GL, Solymos P, Stevens MHH, Szoecs E, Wagner H. 2017. vegan:

822 community ecology package. v.2.5-2. Available at https://cran.r-

823 project.org/package=vegan.

824 Parr CL, Gibb H. 2012. The discovery-dominance trade-off is the exception, rather than the rule.

825 Journal of Animal Ecology 81:233-241 DOI 10.1111/j.1365-2656.2011.01899.x.

826 Polis GA, Strong DR. 1996. Food web complexity and community dynamics. The American

827 Naturalist 147:813-846 DOI 10.1086/285880.

828 Radchenko A, Elmes GW. 2010. Myrmica ants (Hymenoptera: Formicidae) of the Old World.

829 Warszawa: Natura optima dux Foundation.

830 Reifenrath K, Becker C, Poethke HJ. 2012. Diaspore trait preferences of dispersing ants. Journal

831 of Chemical Ecology 38:1093-1104 DOI 10.1007/s10886-012-0174-y.

832 Reitz SR, Trumble JT. 2002. Competitive displacement among insects and arachnids. Annual

833 Review of Entomology 47:435-465 DOI 10.1146/annurev.ento.47.091201.145227.

834 Rosumek FB. 2017. Natural history of ants: what we (do not) know about trophic and temporal

835 niches of neotropical species. Sociobiology 66:244-255 DOI

$836 \quad$ 10.13102/sociobiology.v64i3.1623.

837 Rosumek FB, Brückner A, Blüthgen N, Menzel F, Heethoff M. 2017. Patterns and dynamics of

838 neutral lipid fatty acids in ants - implications for ecological studies. Frontiers in Zoology

839 14:36 DOI 10.1186/s12983-017-0221-1.

840 Ruess L, Chamberlain PM. 2010. The fat that matters: Soil food web analysis using fatty acids 
841

842

843

844

845

846

847

848

849

850

851

852

853

854

855

856

857

858

859

860

861

862

863

and their carbon stable isotope signature. Soil Biology and Biochemistry 42:1898-1910 DOI 10.1016/j.soilbio.2010.07.020.

Ruess L, Schütz K, Migge-Kleian S, Häggblom MM, Kandeler E, Scheu S. 2007. Lipid composition of Collembola and their food resources in deciduous forest standsimplications for feeding strategies. Soil Biology and Biochemistry 39:1990-2000 DOI 10.1016/j.soilbio.2007.03.002.

Schleuning M, Fründ J, Klein AM, Abrahamczyk S, Alarcón R, Albrecht M, Andersson GKS, Bazarian S, Böhning-Gaese K, Bommarco R, Dalsgaard B, Dehling DM, Gotlieb A, Hagen M, Hickler T, Holzschuh A, Kaiser-Bunbury CN, Kreft H, Morris RJ, Sandel B, Sutherland WJ, Svenning JC, Tscharntke T, Watts S, Weiner CN, Werner M, Williams NM, Winqvist C, Dormann CF, Blüthgen N. 2012. Specialization of mutualistic interaction networks decreases toward tropical latitudes. Current Biology 22:1925-1931 DOI 10.1016/j.cub.2012.08.015.

Schluter D. 2000. Ecological character displacement in adaptive radiation. The American Naturalist 156:S4-S16 DOI 10.1086/303412.

Seifert B. 2007. Die Ameisen Mittel- und Nordeuropas. Tauer: Lutra.

Seifert B, Schultz R. 2009. A taxonomic revision of the Formica rufibarbis Fabricius, 1793 group (Hymenoptera: Formicidae). Myrmecological News 12:255-272 DOI 10.1007/s12275-007-0115-6.

Snealling RR, Longino JT. 1992. Revisionary notes on the fungus-growing ants of the genus Cyphomyrmex, rimosus group (Hymenoptera: Formicidae: Attini). In: Quintero D, Aiello A, eds. Insects of Panama and Mesoamerica: selected studies. Oxford: Oxford University Press, 479-494. 
864 Sponheimer M, Robinson TF, Roeder BL, Passey BH, Ayliffe LK, Cerling TE, Dearing MD,

865 Ehleringer JR. 2003. An experimental study of nitrogen flux in llamas: is ${ }^{14} \mathrm{~N}$ preferentially

866 excreted? Journal of Archaeological Science 30:1649-1655 DOI 10.1016/S0305-

$867 \quad$ 4403(03)00066-9.

868 Stanley-Samuelson DW, Jurenka RA, Cripps C, Blomquist GJ, de Renobales M. 1988. Fatty 869 acids in insects: composition, metabolism, and biological significance. Archives of Insect 870 Biochemistry and Physiology 9:1-33 DOI 10.1002/arch.940090102.

871 Sun Q, Zhou X. 2013. Corpse management in social insects. International Journal of Biological $872 \quad$ Sciences 9:313-321 DOI doi: 10.7150/ijbs.5781.

873 R Core Team. 2017. R: a language and environment for statistical computing. v.3.4.3. Available $874 \quad$ at https://www.R-project.org.

875 Thompson SN. 1973. A review and comparative characterization of the fatty acid compositions 876 of seven insect orders. Comparative Biochemistry and Physiology Part B: Comparative 877 Biochemistry 45:467-482 DOI 10.1016/0305-0491(73)90078-3.

878 Tillberg CV, McCarthy DP, Dolezal AG, Suarez AV. 2006. Measuring the trophic ecology of 879 ants using stable isotopes. Insectes Sociaux 53:65-69 DOI 10.1007/s00040-005-0836-7.

880 Webb SC, Hedges RE, Simpson SJ. 1998. Diet quality influences the d13C and d15N of locusts 881 and their biochemical components. Journal of Experimental Biology 201:2903-2911.

882 Whitaker D, Christman M. 2015. clustsig: significant cluster analysis. v.1.1. Available at 883 https://CRAN.R-project.org/package=clustsig.

884 Wild AL. 2007. Taxonomic revision of the ant genus Linepithema (Hymenoptera:Formicidae).

885 Berkeley: University of California Press.

886 Wilson EO. 2003. Pheidole in the New World: a dominant, hyperdiverse ant genus. Cambridge: 
887 Harvard University Press.

888 


\section{Figure 1 (on next page)}

UPGMA clustering of resources and species in Brazil $(a, c)$ and Germany $(b, d)$, based on Bray-Curtis dissimilarities.

Red lines link elements from the same statistically significant cluster (SIMPROF, $p<0.05$ ). 
(a)
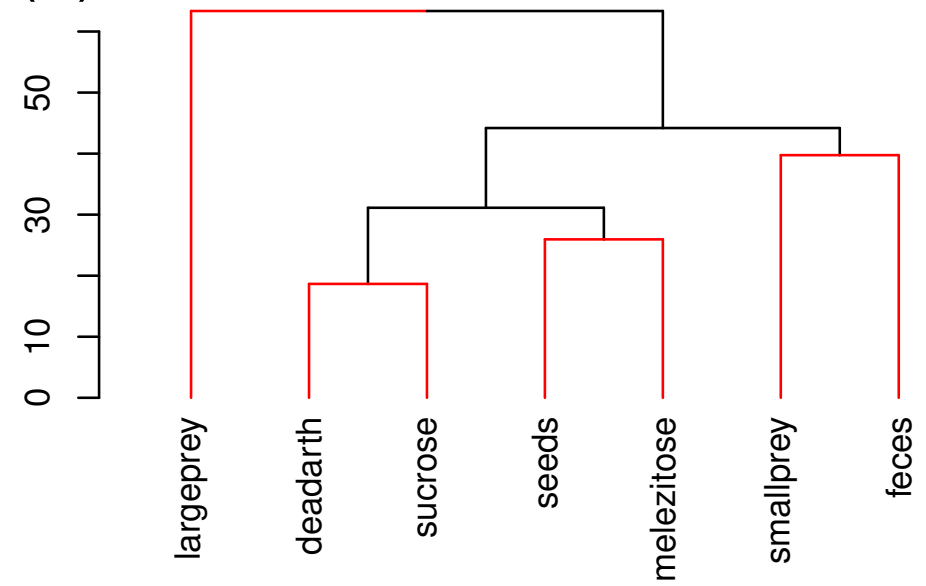

(c)

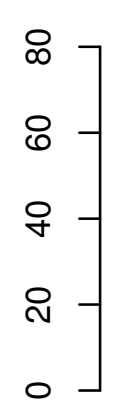

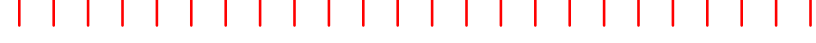

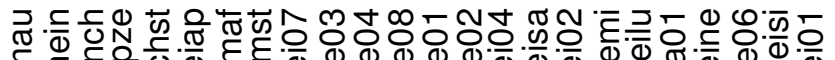
દ. ๙
(B) ${ }^{\text {script to be reviewed }}$

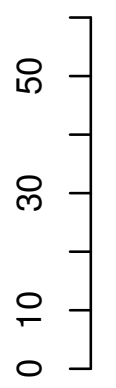

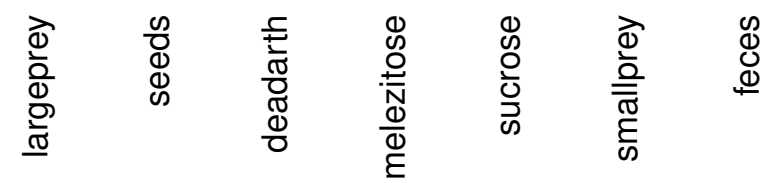

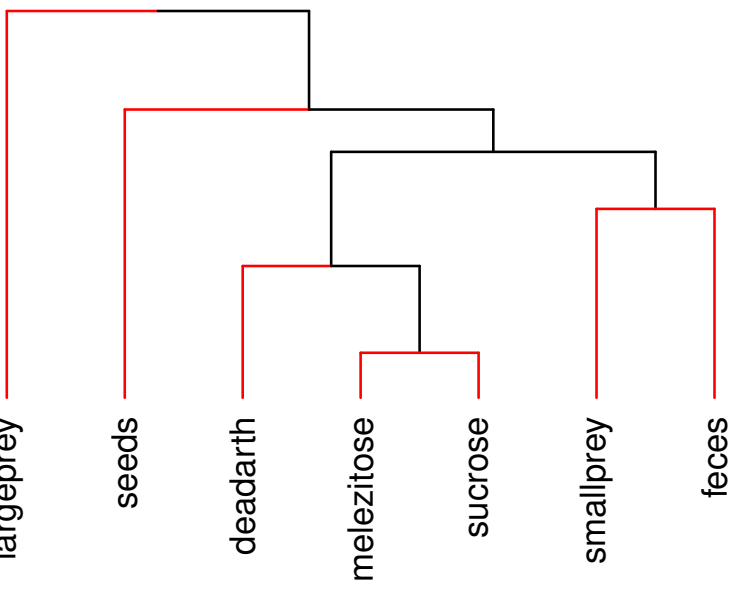

(d)

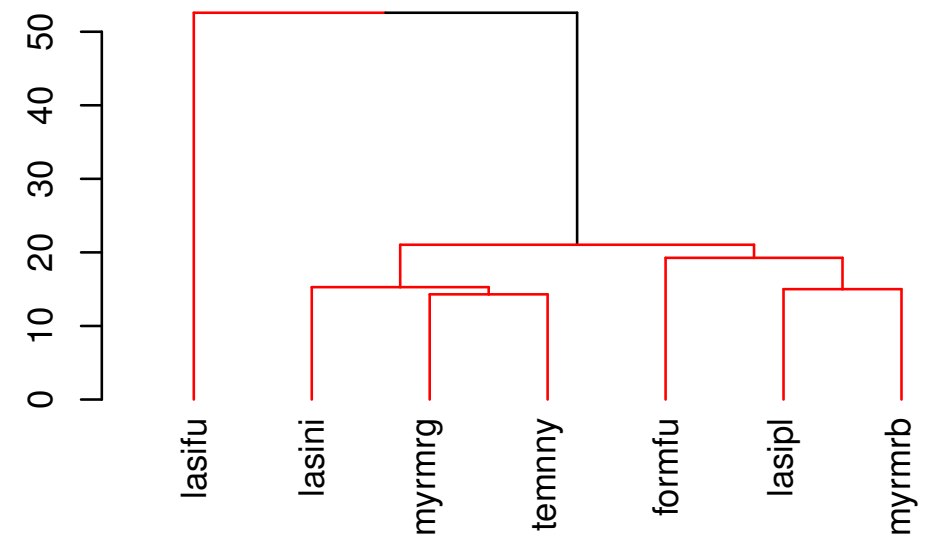




\section{Figure 2 (on next page)}

Comparison of the three most abundant NLFAs, total amounts and unsaturation indexes between tropical and temperate species.

Green $=$ tropical species; red $=$ temperate species. Significant differences are in bold (MannWhitney test). 


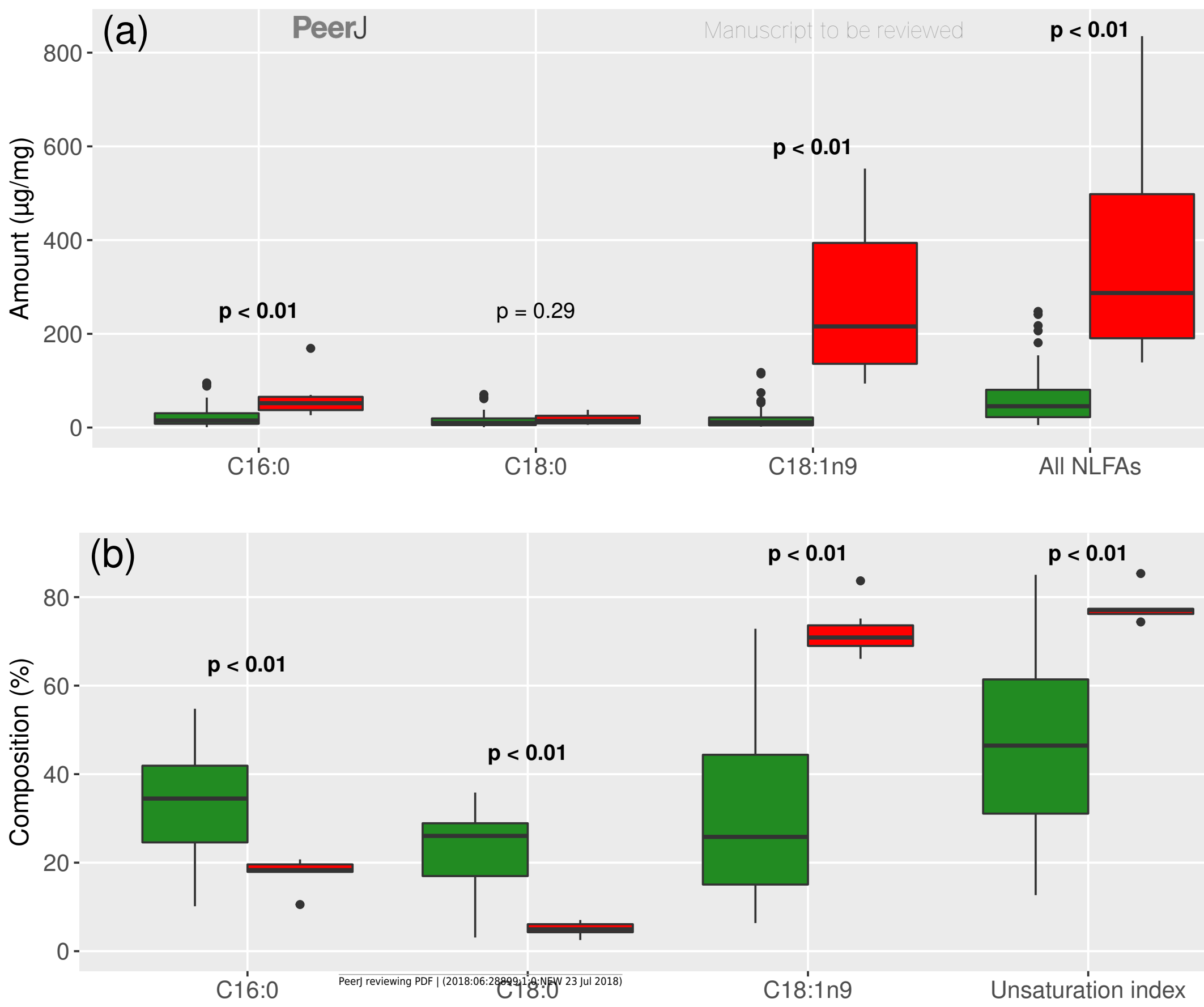




\section{Figure 3 (on next page)}

Networks of resource use and fatty acid composition in Brazil (a) and Germany (b).

Species labels are standardized to represent $100 \%$ of resource use/NLFA composition. The width of connecting lines represents proportion of bait use/NLFA abundance for each species. Bait/NLFA labels show the sum of proportions for the whole community. Only species analyzed with all three methods are included. 


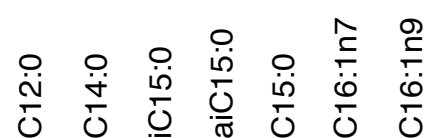

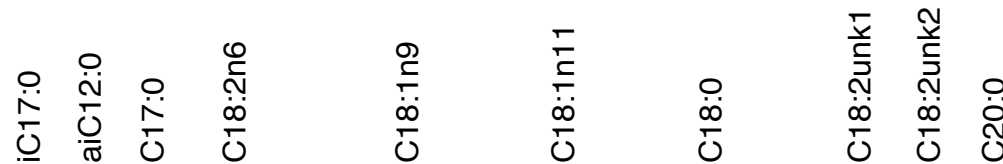
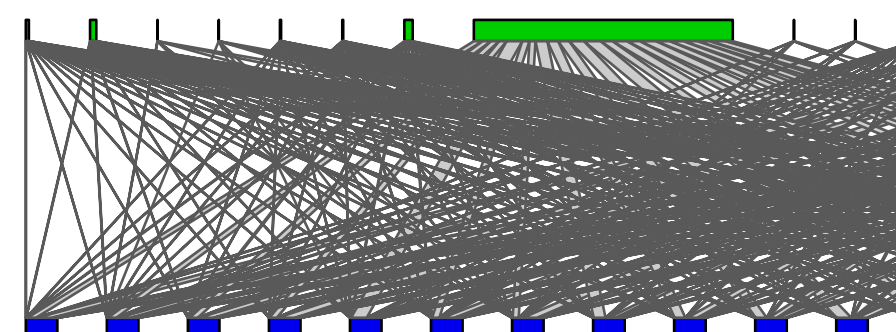

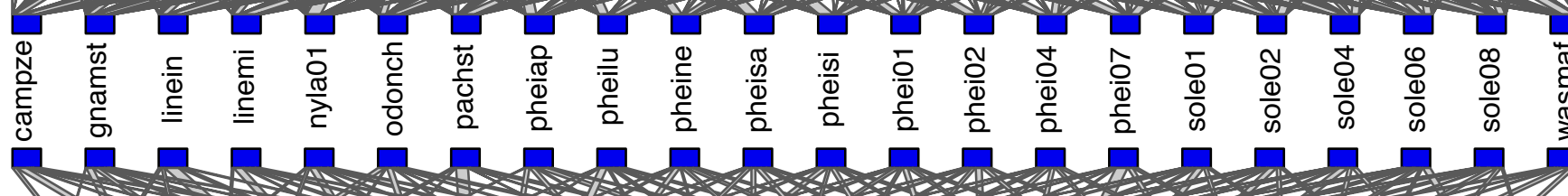

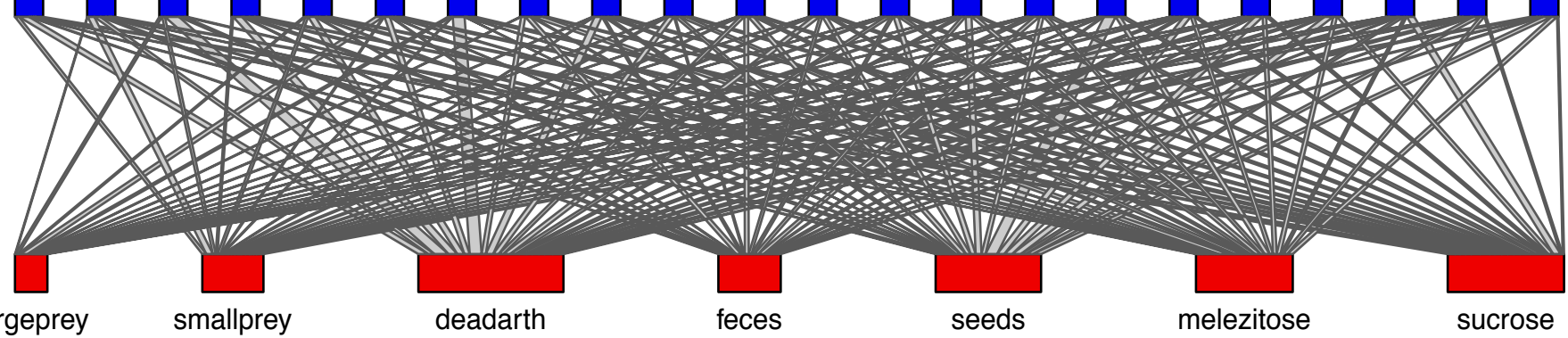

(b)
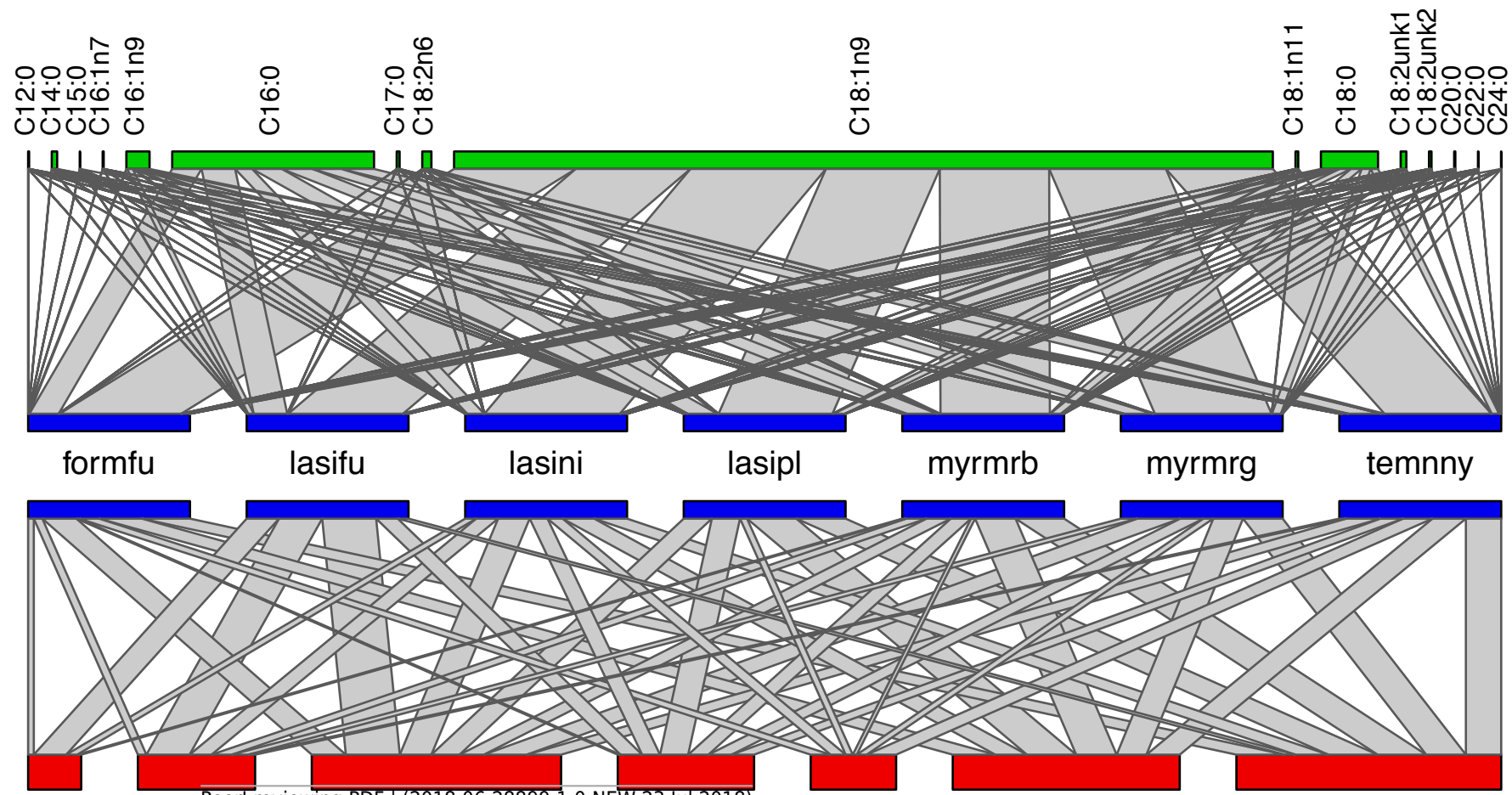

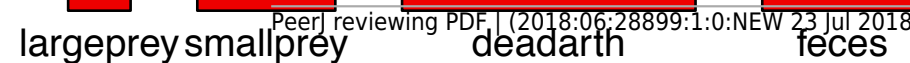

seeds

melezitose

sucrose 
Figure 4 (on next page)

Principal Component Analysis of resource use in Brazil (a) and Germany (b).

Blue setae $=$ bait direction vectors. Red setae $=$ NLFAs correlated to the two main PC axes (Envfit; only statistically significant relationships are plotted). Setae sizes indicate relative strength of the relationships, but are scaled independently for each plot. Only species analyzed with all three methods are included. 

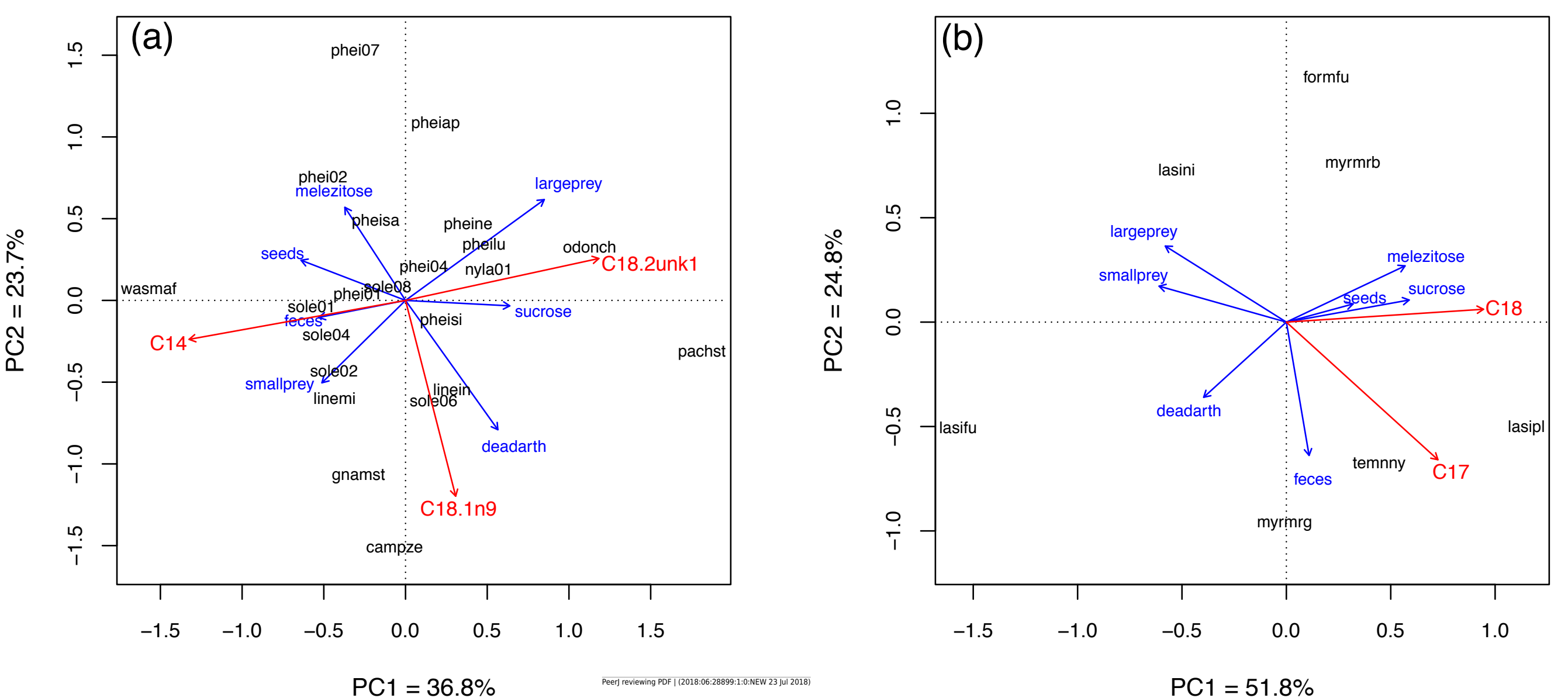


\section{Figure $\mathbf{5}$ (on next page)}

Stable isotope signatures of species in Brazil (a) and Germany (b).

Grey bars display standard deviations for species averages. $\delta^{15} \mathrm{~N}$ and $\delta^{13} \mathrm{C}$ are displayed in $\%$, following the equation described in the methods. 


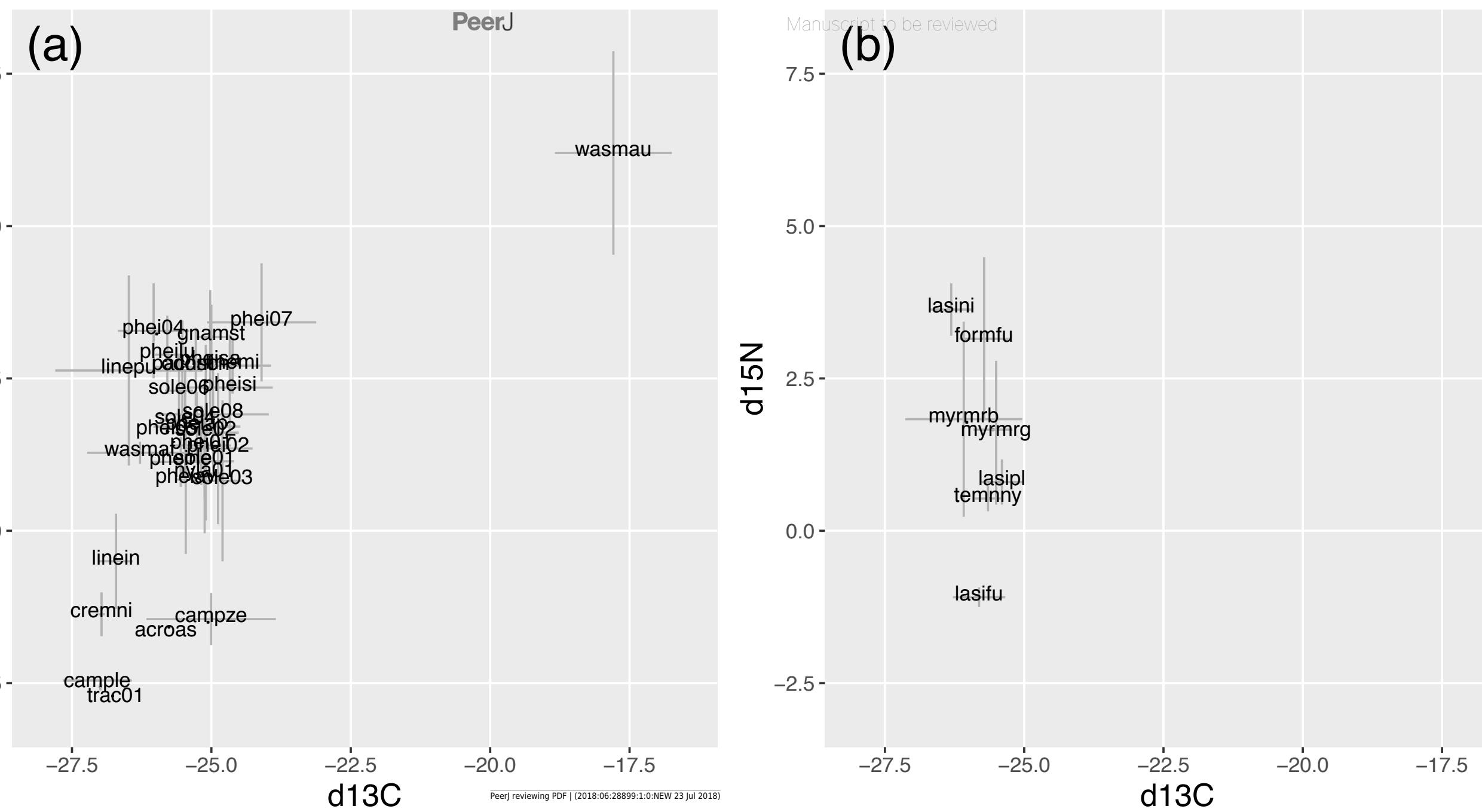




\section{Figure 6 (on next page)}

Relation between specialization indices ( $\left.d^{\prime}\right)$ for bait use and NLFAs.

Green $=$ tropical species, the dashed line indicates significant correlation; red $=$ temperate species, no correlation observed. Only species analyzed with all three methods are included. 


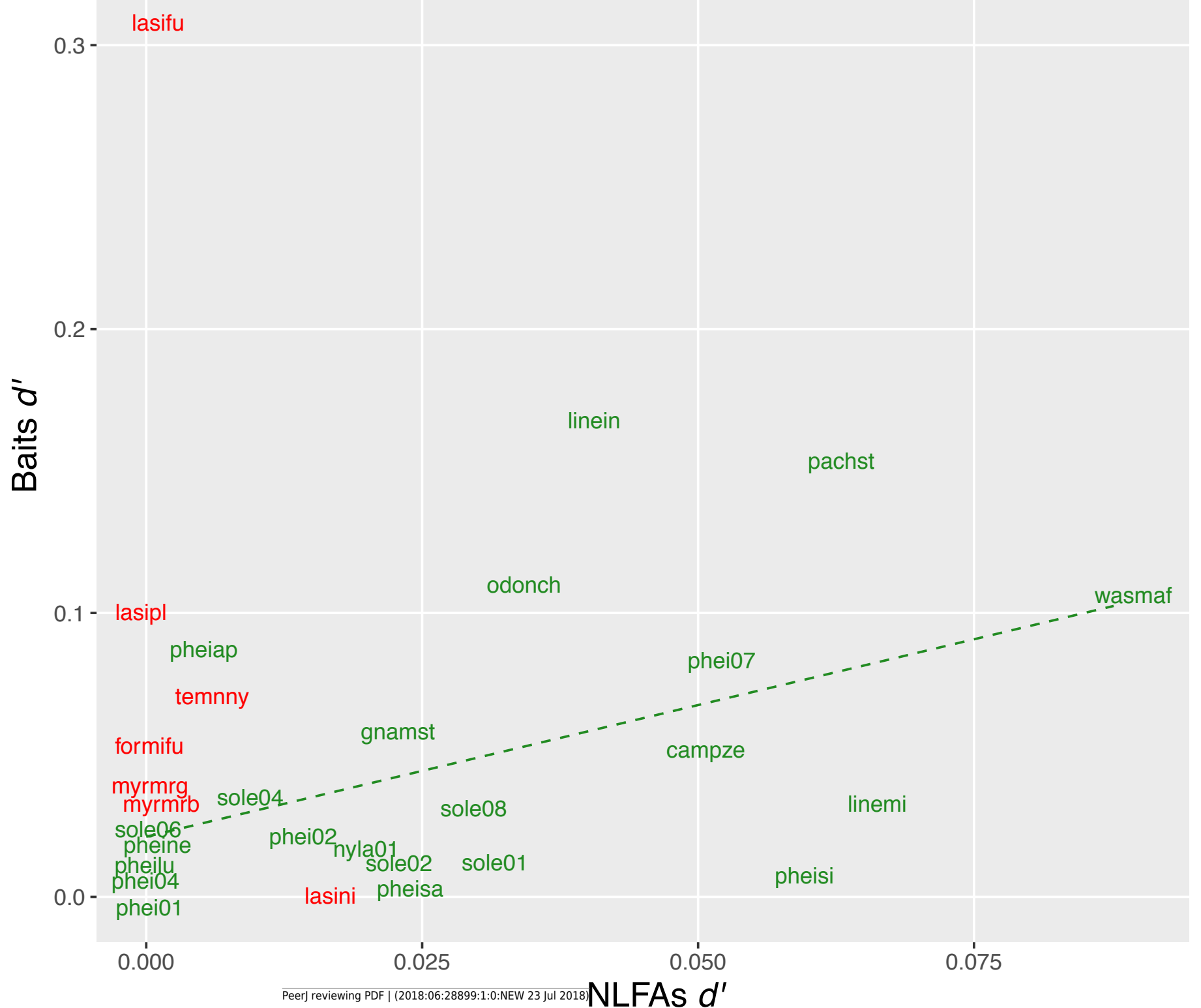




\section{Table $\mathbf{1}$ (on next page)}

Details of the sampling design applied in this study. 
1 Details of the sampling design applied in this study.

\begin{tabular}{|c|c|c|}
\hline & Brazil & Germany \\
\hline \multicolumn{3}{|l|}{ Sampling effort } \\
\hline Sampling points & 64 & 80 \\
\hline Period of the day & Day and night & Day \\
\hline Baits & $\begin{array}{l}64 \text { per resource per period } \\
\quad \text { (= 896 baits) }\end{array}$ & $\begin{array}{l}80 \text { per resource } \\
\text { (= } 560 \text { baits })\end{array}$ \\
\hline Pitfall sampling & $\begin{array}{l}\text { Three 10-hour rounds per period } \\
\text { (=60 hours })\end{array}$ & $\begin{array}{l}\text { Three 12-hour rounds } \\
\qquad(=36 \text { hours })\end{array}$ \\
\hline \multicolumn{3}{|l|}{ Resource represented } \\
\hline Larger, faster and harder prey & \multicolumn{2}{|c|}{ Living crickets (Achaeta domesticus Linnaeus, 1758) } \\
\hline Smaller, slower and softer prey & $\begin{array}{l}\text { Living termites } \\
\text { (Nasutitermitinae) }\end{array}$ & $\begin{array}{c}\text { Living maggots } \\
\text { (Lucilia sericata Meigen, 1826) }\end{array}$ \\
\hline Dead arthropods & \multicolumn{2}{|c|}{$\begin{array}{l}\text { Crushed crickets and maggots/mealworms } \\
\text { (Tenebrio molitor Linnaeus, 1758) }\end{array}$} \\
\hline Bird droppings & \multicolumn{2}{|c|}{ Chicken feces from organic breeding } \\
\hline Seeds & $\begin{array}{l}\text { Seed mixture of diverse sizes and } \\
\text { shapes, without elaiosomes }\end{array}$ & $\begin{array}{l}\text { Seeds of Chelidonium majus (L.), } \\
\text { with elaiosomes }\end{array}$ \\
\hline Oligosaccharides in honeydew & \multicolumn{2}{|c|}{ Melezitose $20 \%$} \\
\hline Disaccharides in nectar and fruits & \multicolumn{2}{|c|}{ Sucrose $20 \%$} \\
\hline
\end{tabular}

2 


\section{Table 2 (on next page)}

Resource use of ant species in Brazil and Germany.

Values for the seven baits are given in \% of the total records for each species. Only species with at least 10 records from 5 sample points are listed. 


\section{Resource use of ant species in Brazil and Germany.}

2 Values for the seven baits are given in $\%$ of the total records for each species. Only species with 3 at least 10 records from 5 sample points are listed.

\begin{tabular}{|c|c|c|c|c|c|c|c|c|c|c|}
\hline Species & 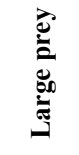 & 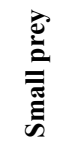 & 莺 & 遶 & ङ్ & 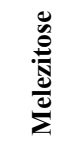 & 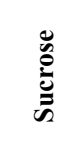 & $i$ & 总 & 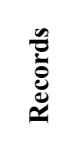 \\
\hline \multicolumn{11}{|l|}{ Brazil } \\
\hline Camponotus zenon & - & 14 & 36 & 7 & 7 & 7 & 29 & 0.06 & 1.6 & 14 \\
\hline Gnamptogenys striatula & 2 & 23 & 21 & 19 & 11 & 6 & 17 & 0.04 & 1.8 & 47 \\
\hline Linepithema iniquum & 10 & 10 & 50 & 20 & - & 10 & - & 0.16 & 1.4 & 10 \\
\hline Linepithema micans & - & 6 & 31 & 6 & 19 & 19 & 19 & 0.03 & 1.7 & 16 \\
\hline Nylanderia sp.1 & 7 & 10 & 25 & 6 & 9 & 23 & 21 & 0.03 & 1.8 & 267 \\
\hline Odontomachus chelifer & 26 & 5 & 19 & 5 & 5 & 10 & 31 & 0.12 & 1.7 & 42 \\
\hline Pachycondyla striata & 14 & 3 & 42 & - & 1 & 6 & 34 & 0.16 & 1.3 & 88 \\
\hline Pheidole aper & 4 & - & 15 & 19 & 7 & 37 & 19 & 0.08 & 1.6 & 27 \\
\hline Pheidole lucretii & 4 & 4 & 26 & 8 & 14 & 20 & 24 & 0.02 & 1.8 & 50 \\
\hline Pheidole nesiota & 4 & 9 & 20 & 4 & 16 & 25 & 21 & 0.02 & 1.8 & 89 \\
\hline Pheidole sarcina & 4 & 8 & 16 & 14 & 20 & 18 & 22 & 0.01 & 1.9 & 51 \\
\hline Pheidole sigillata & 4 & 10 & 24 & 10 & 16 & 13 & 22 & 0.00 & 1.8 & 91 \\
\hline Pheidole sp.1 & 3 & 13 & 19 & 10 & 18 & 17 & 21 & 0.01 & 1.9 & 101 \\
\hline Pheidole sp.2 & 6 & 11 & 14 & 14 & 21 & 20 & 15 & 0.01 & 1.9 & 322 \\
\hline Pheidole sp.4 & 5 & 6 & 21 & 19 & 14 & 14 & 21 & 0.01 & 1.9 & 78 \\
\hline Pheidole sp.7 & 6 & 6 & 6 & 6 & 41 & 18 & 18 & 0.08 & 1.6 & 17 \\
\hline Solenopsis sp.1 & 4 & 14 & 18 & 13 & 26 & 12 & 13 & 0.01 & 1.8 & 141 \\
\hline Solenopsis sp.2 & 2 & 14 & 24 & 7 & 28 & 13 & 13 & 0.03 & 1.8 & 180 \\
\hline Solenopsis sp. $3^{*}$ & - & 4 & 16 & 8 & 32 & 20 & 20 & 0.05 & 1.6 & 25 \\
\hline Solenopsis sp.4 & 1 & 5 & 21 & 10 & 31 & 14 & 18 & 0.03 & 1.7 & 96 \\
\hline Solenopsis sp.6 & 2 & 10 & 29 & 7 & 17 & 10 & 26 & 0.02 & 1.7 & 42 \\
\hline Solenopsis sp.8 & 7 & 11 & 29 & 7 & 25 & 14 & 7 & 0.03 & 1.8 & 28 \\
\hline Wasmannia affinis & - & 25 & 10 & 10 & 30 & 20 & 5 & 0.09 & 1.6 & 20 \\
\hline Wasmannia auropunctata* & - & - & - & 100 & - & - & - & 0.62 & 0 & 19 \\
\hline$d^{\prime}$ & 0.17 & 0.09 & 0.09 & 0.24 & 0.14 & 0.07 & 0.09 & $\mathrm{H}_{2}{ }^{\prime}=\mathbf{0 . 1 3}$ & & \\
\hline Total richness $\dagger$ & 26 & 31 & 33 & 32 & 32 & 34 & 34 & & & \\
\hline Total records $\uparrow$ & 107 & 203 & 422 & 215 & 344 & 327 & 366 & & & \\
\hline \multicolumn{11}{|l|}{ Germany } \\
\hline Formica fusca & 4 & 5 & 21 & 2 & 12 & 26 & 30 & 0.06 & 1.6 & 57 \\
\hline Lasius fuliginosus & 20 & 27 & 33 & 13 & - & - & 7 & 0.31 & 1.5 & 15 \\
\hline Lasius niger & 7 & 14 & 19 & 11 & 9 & 19 & 20 & 0.01 & 1.9 & 118 \\
\hline Lasius platythorax & - & - & 17 & 17 & 4 & 30 & 30 & 0.11 & 1.5 & 23 \\
\hline Myrmica rubra & 3 & 13 & 15 & 13 & 3 & 25 & 30 & 0.03 & 1.7 & 40 \\
\hline Myrmica ruginodis & - & 10 & 27 & 14 & 6 & 18 & 24 & 0.03 & 1.7 & 49 \\
\hline Temnothorax nylanderi & - & 4 & 21 & 14 & 18 & 21 & 22 & 0.06 & 1.7 & 165 \\
\hline$d^{\prime}$ & 0.29 & 0.14 & 0.02 & 0.05 & 0.13 & 0.11 & 0.05 & $\mathrm{H}_{2}{ }^{\prime}=0.12$ & & \\
\hline Total richness $\dagger$ & 4 & 8 & 8 & 8 & 7 & 9 & 11 & & & \\
\hline Total records $\dagger$ & 14 & 42 & 99 & 56 & 54 & 102 & 116 & & & \\
\hline
\end{tabular}




\section{Table 3(on next page)}

Fatty acid profiles of ant species in Brazil and Germany.

Average individual NLFA abundances are given in $\%$ of the total composition. 


\section{Fatty acid profiles of ant species in Brazil and Germany.}

2 Average individual NLFA abundances are given in $\%$ of the total composition.

\begin{tabular}{|c|c|c|c|c|c|c|c|c|c|c|c|c|c|c|c|c|c|c|c|c|c|c|c|c|c|}
\hline Species & 䒕 & $\underset{\ddot{\dot{U}}}{ }$ & 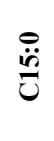 & 节 & & 苞 & $\begin{array}{l}\widehat{\Xi} \\
\ddot{U}\end{array}$ & $\frac{\hat{\Xi}}{\ddot{U}}$ & 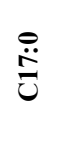 & 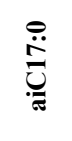 & & $\begin{array}{l}\stackrel{\ddot{\theta}}{\dot{\theta}} \\
\stackrel{0}{0}\end{array}$ & $\begin{array}{l}\stackrel{\Xi}{\Xi} \\
\ddot{0} \\
\ddot{0}\end{array}$ & $\begin{array}{l}\exists \\
\ddot{\ddot{\theta}} \\
\ddot{U}\end{array}$ & 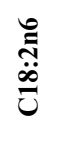 & 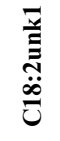 & 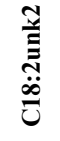 & 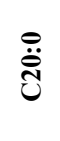 & تِت & 芒 & $i$ & $\begin{array}{l}\bar{\Xi} \\
\bar{E} \\
\text { Ё }\end{array}$ & 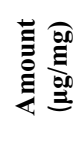 & 5 & $\frac{\mathscr{e}}{\bar{E}}$ \\
\hline \multicolumn{26}{|l|}{ Brazil } \\
\hline Acanthognathus brevicornis* & 0.3 & 1.0 & 0.4 & - & 0.3 & 28 & 0.3 & 0.3 & 0.5 & 0.04 & 0.1 & 24 & 24 & 2.0 & 11 & 3.6 & 2.8 & 0.8 & - & - & 0.01 & 1.8 & 60 & 61 & 2 \\
\hline Acanthognathus ocellatus* & 0.4 & 0.9 & 0.3 & 0.01 & 0.04 & 38 & 0.1 & 0.4 & 0.4 & - & - & 30 & 21 & 1.1 & 5.4 & 1.4 & 1.0 & 0.5 & - & - & 0.01 & 1.5 & 65 & 38 & 2 \\
\hline Acromyrmex aspersus* & 0.3 & 1.3 & 0.1 & - & - & 31 & 0.1 & 4.3 & 0.1 & - & - & 21 & 29 & 1.2 & 5.7 & 2.4 & 1.8 & 0.8 & - & - & 0.01 & 1.7 & 13 & 55 & 2 \\
\hline Acromyrmex laticeps* & 0.2 & 0.2 & 0.1 & - & - & 10 & - & 0.2 & 0.5 & - & - & 16 & 37 & 1.1 & 23 & 6.0 & 5.1 & 0.5 & - & - & 0.09 & 1.7 & 8 & 106 & 1 \\
\hline Acromyrmex lundii* & 0.2 & 0.4 & 0.0 & - & - & 13 & - & 0.4 & 0.2 & - & - & 21 & 44 & 1.8 & 11 & 4.2 & 3.7 & 0.4 & - & - & 0.04 & 1.6 & 6 & 84 & 1 \\
\hline Acromyrmex subterraneus* & 0.1 & 0.2 & 0.1 & 0.01 & 0.03 & 10 & 0.2 & 0.5 & 0.4 & 0.03 & 0.01 & 18 & 44 & 1.2 & 17 & 4.0 & 3.6 & 0.5 & - & - & 0.06 & 1.6 & 30 & 95 & 2 \\
\hline Azteca sp. $2^{*}$ & 0.5 & 0.3 & 0.0 & - & - & 13 & 0.1 & 0.4 & 0.1 & - & - & 10 & 73 & 0.8 & 1.0 & 0.7 & 0.5 & 0.2 & - & - & 0.10 & 1.0 & 62 & 78 & 3 \\
\hline Camponotus lespesii* & 0.3 & 0.4 & 0.2 & - & - & 30 & 0.2 & 1.4 & 0.1 & - & - & 18 & 48 & 0.6 & 0.6 & 0.3 & 0.2 & 0.2 & - & - & 0.03 & 1.3 & 11 & 52 & 2 \\
\hline Camponotus zenon & 0.6 & 1.0 & 0.2 & - & - & 28 & 0.2 & 2.8 & 0.3 & - & - & 15 & 50 & 0.8 & 0.8 & 0.2 & 0.1 & 0.1 & - & - & 0.03 & 1.3 & 5 & 56 & 2 \\
\hline Cephalotes pallidicephalus* & 0.1 & 0.8 & 0.0 & 0.1 & 0.1 & 25 & - & 6.0 & 0.1 & - & - & 3 & 60 & 4.4 & 0.5 & - & - & 0.4 & - & - & 0.11 & 1.2 & 95 & 71 & 2 \\
\hline Cephalotes pusillus* & 0.7 & 1.0 & 0.2 & - & - & 17 & 3.1 & 2.5 & 0.3 & - & - & 12 & 61 & 1.9 & 0.4 & - & - & 0.8 & - & - & 0.09 & 1.3 & 36 & 69 & 1 \\
\hline Crematogaster nigropilosa* & 0.2 & 1.0 & 0.0 & - & - & 27 & 0.3 & 0.5 & 0.2 & - & - & 17 & 48 & 0.6 & 3.1 & 1.1 & 0.6 & 0.4 & - & - & 0.02 & 1.4 & 154 & 59 & 6 \\
\hline Cyphomyrmex rimosus* & 0.5 & 1.6 & 0.2 & - & - & 38 & 0.1 & 2.7 & 0.3 & 0.04 & - & 34 & 15 & 1.0 & 3.7 & 1.0 & 0.8 & 0.5 & - & - & 0.02 & 1.5 & 86 & 30 & 4 \\
\hline Gnamptogenys striatula & 0.2 & 1.0 & 0.3 & 0.01 & 0.3 & 27 & 0.5 & 1.1 & 0.6 & 0.1 & 0.2 & 18 & 39 & 2.4 & 6.0 & 1.9 & 1.4 & 0.7 & - & - & 0.01 & 1.7 & 56 & 61 & 6 \\
\hline Hylomyrma reitteri* & 0.7 & 1.1 & - & - & - & 55 & - & - & 0.4 & - & - & 29 & 9 & 0.6 & 3.0 & 1.1 & 0.6 & - & - & - & 0.05 & 1.2 & 22 & 19 & 1 \\
\hline Linepithema iniquum & 0.1 & 0.8 & 0.1 & - & - & 26 & 0.4 & 4.2 & 0.2 & - & - & 15 & 47 & 0.9 & 2.6 & 1.1 & 0.7 & 0.4 & - & - & 0.02 & 1.5 & 248 & 62 & 3 \\
\hline Linepithema micans & 0.4 & 0.7 & 0.1 & - & - & 24 & 0.1 & 0.2 & 0.2 & - & - & 16 & 56 & 0.5 & 1.4 & 0.3 & 0.2 & 0.2 & - & - & 0.04 & 1.2 & 94 & 61 & 4 \\
\hline Nylanderia sp.1 & 0.4 & 0.7 & 0.2 & 0.01 & - & 49 & 0.1 & 2.1 & 0.2 & - & - & 28 & 15 & 0.7 & 3.1 & 0.4 & 0.3 & 0.1 & - & - & 0.03 & 1.3 & 31 & 25 & 11 \\
\hline Octostruma petiolata* & 0.5 & 1.4 & 0.3 & 0.1 & 0.2 & 42 & 0.3 & 1.4 & 0.8 & 0.1 & 0.1 & 36 & 12 & 1.2 & 2.0 & 0.6 & 0.4 & 0.5 & - & - & 0.03 & 1.4 & 85 & 21 & 4 \\
\hline Odontomachus chelifer & 0.2 & 0.7 & 0.2 & 0.1 & 0.1 & 23 & 0.3 & 1.9 & 0.6 & 0.1 & 0.1 & 16 & 38 & 1.7 & 9.4 & 4.2 & 2.5 & 0.8 & - & - & 0.02 & 1.8 & 17 & 74 & 10 \\
\hline Pachycondyla harpax* & 0.3 & 0.5 & 0.1 & 0.1 & 0.1 & 19 & 0.1 & 0.3 & 0.6 & - & - & 22 & 40 & 0.8 & 9.0 & 3.1 & 2.9 & 0.3 & - & - & 0.02 & 1.6 & 12 & 72 & 1 \\
\hline Pachycondyla striata & 0.1 & 0.5 & 0.1 & 0.02 & 0.1 & 19 & 0.1 & 1.2 & 0.4 & 0.03 & 0.1 & 13 & 46 & 1.1 & 13 & 3.7 & 2.0 & 0.4 & - & - & 0.04 & 1.6 & 47 & 85 & 16 \\
\hline Pheidole aper & 0.6 & 0.8 & 0.1 & - & - & 38 & 0.1 & 0.3 & 0.3 & - & - & 25 & 23 & 0.3 & 9.1 & 1.5 & 1.3 & - & - & - & 0.01 & 1.5 & 27 & 47 & 9 \\
\hline Pheidole lucretii & 0.3 & 0.7 & 0.2 & - & - & 34 & 0.1 & 0.4 & 0.4 & - & - & 21 & 32 & 1.2 & 5.7 & 1.9 & 1.5 & 0.2 & - & - & $<0.01$ & 1.5 & 59 & 52 & 12 \\
\hline Pheidole nesiota & 0.4 & 0.7 & 0.1 & - & - & 35 & 0.1 & 0.3 & 0.3 & - & - & 27 & 25 & 0.4 & 6.4 & 2.1 & 1.6 & 0.1 & - & - & $<0.01$ & 1.5 & 58 & 46 & 6 \\
\hline
\end{tabular}


5 (cont.) Fatty acid profiles of ant species in Brazil and Germany.

6 Average individual NLFA abundances are given in $\%$ of the total composition.

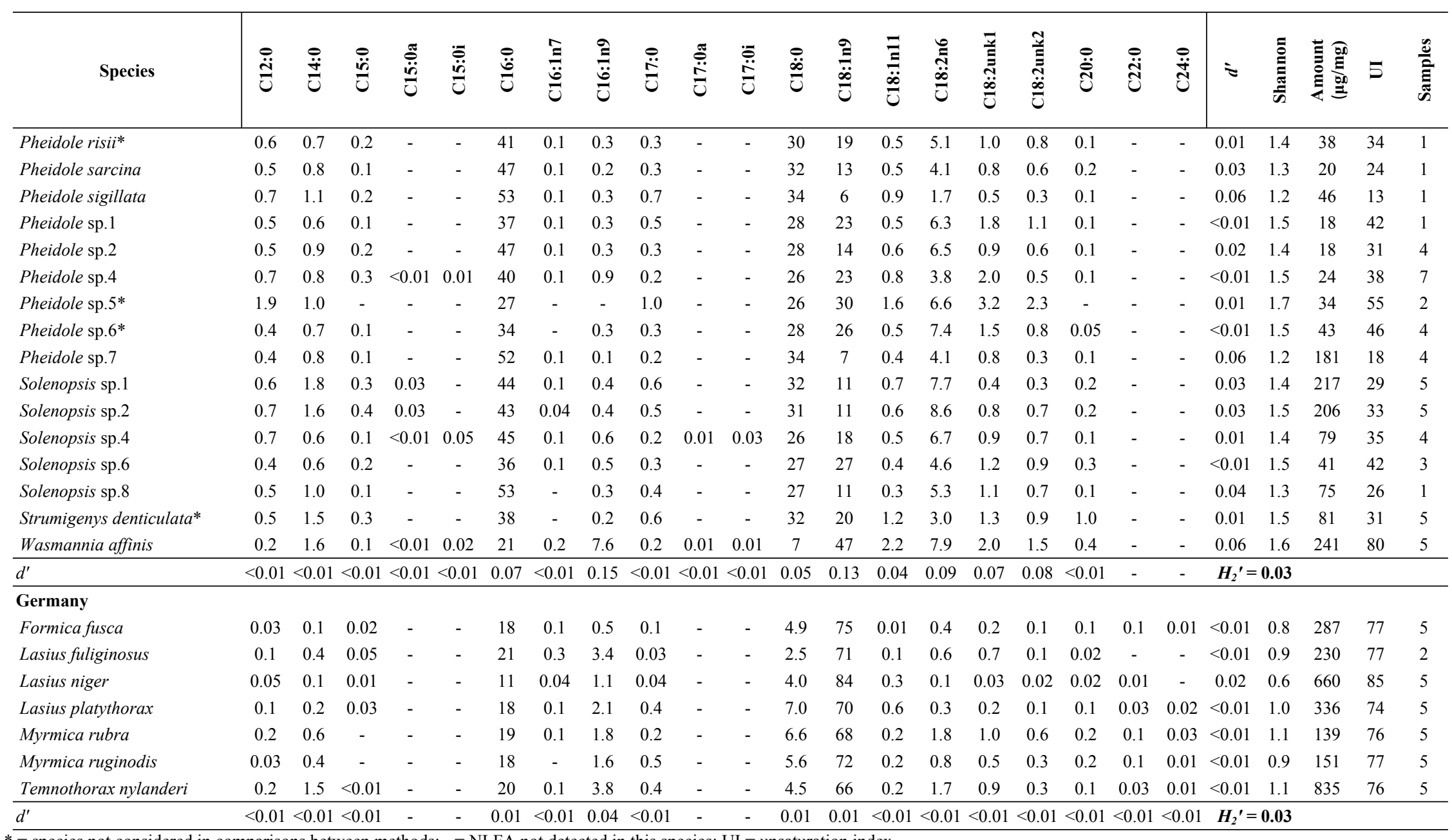




\section{Table 4 (on next page)}

Stable isotope signatures of ant species in Brazil and Germany.

Average $\delta^{15} \mathrm{~N}$ and $\delta^{13} \mathrm{C}$ are given in \%o, following the equation described in the methods. 


\section{Stable isotope signatures of ant species in Brazil and Germany.}

2 Average $\delta^{15} \mathrm{~N}$ and $\delta^{13} \mathrm{C}$ are given in \%o, following the equation described in the methods.

\begin{tabular}{|c|c|c|c|c|c|c|c|}
\hline Species & $\delta^{15} \mathbf{N}$ & $\delta^{13} \mathbf{C}$ & Samples & Species & $\delta^{15} \mathbf{N}$ & $\delta^{13} \mathbf{C}$ & Samples \\
\hline \multicolumn{8}{|l|}{ Brazil } \\
\hline Acromyrmex aspersus* & 3.42 & -25.76 & 1 & Pheidole sp.5* & 6.63 & -25.79 & 1 \\
\hline Camponotus lespesii* & 2.44 & -26.99 & 3 & Pheidole sp.7 & 8.42 & -24.10 & 5 \\
\hline Camponotus zenon & 3.50 & -25.06 & 4 & Solenopsis sp.1 & 6.14 & -25.12 & 5 \\
\hline Crematogaster nigropilosa* & 3.63 & -26.97 & 2 & Solenopsis sp.2 & 6.61 & -25.10 & 5 \\
\hline Gnamptogenys striatula & 8.18 & -25.00 & 5 & Solenopsis sp. $3^{*}$ & 5.82 & -24.80 & 3 \\
\hline Linepithema iniquum & 4.50 & -26.71 & 5 & Solenopsis sp.4 & 6.81 & -25.47 & 5 \\
\hline Linepithema micans & 7.71 & -24.62 & 4 & Solenopsis sp.6 & 7.30 & -25.58 & 5 \\
\hline Linepithema pulex* & 7.63 & -26.48 & 4 & Solenopsis sp. 8 & 6.91 & -24.97 & 3 \\
\hline Nylanderia sp.1 & 5.94 & -25.12 & 5 & Trachymyrmex sp. $1^{*}$ & 2.29 & -26.77 & 1 \\
\hline Odontomachus chelifer & 7.69 & -25.28 & 5 & Wasmannia affinis & 6.28 & -26.28 & 4 \\
\hline Pachycondyla striata & 7.69 & -25.52 & 5 & Wasmannia auropunctata* & 11.20 & -17.79 & 4 \\
\hline Pheidole aper & 6.71 & -25.26 & 5 & Germany & & & \\
\hline Pheidole avia* & 5.84 & -25.46 & 3 & Formica fusca & 3.15 & -25.72 & 5 \\
\hline Pheidole lucretii & 7.89 & -25.79 & 3 & Lasius fuliginosus & -1.09 & -25.81 & 5 \\
\hline Pheidole nesiota & 6.13 & -25.55 & 5 & Lasius niger & 3.63 & -26.31 & 5 \\
\hline Pheidole sarcina & 7.77 & -25.02 & 4 & Lasius platythorax & 0.80 & -25.40 & 5 \\
\hline Pheidole sigillata & 7.35 & -24.67 & 5 & Myrmica rubra & 1.78 & -26.03 & 5 \\
\hline Pheidole sp.1 & 6.40 & -25.18 & 5 & Myrmica ruginodis & 1.66 & -25.56 & 5 \\
\hline Pheidole sp.2 & 6.35 & -24.88 & 5 & Temnothorax nylanderi & 0.53 & -25.65 & 5 \\
\hline Pheidole sp.4 & 8.23 & -25.98 & 5 & & & & \\
\hline
\end{tabular}

$3 *=$ species not considered in comparisons between methods. 


\section{Table 5 (on next page)}

Correlations between methods in Brazil and Germany.

Results are for Mantel tests using Spearman's rho, based on similarities matrices (Bray-Curtis for baits and NLFAs, Euclidean distances for isotopes). Asterisks indicate significant correlations. 


\section{Correlations between methods in Brazil and Germany.}

2 Results are for Mantel tests using Spearman's rho, based on similarities matrices (Bray-Curtis for

3 baits and NLFAs, Euclidean distances for isotopes). Asterisks indicate significant correlations.

\begin{tabular}{lcccc}
\hline \multicolumn{1}{c}{ Method } & \multicolumn{2}{c}{ Baits } & \multicolumn{2}{c}{ NLFAs } \\
& rho & $\mathrm{p}$ & rho & $\mathrm{p}$ \\
\hline Brazil & & & & \\
NLFAs & 0.43 & $<0.01^{*}$ & & \\
$\delta^{13} \mathrm{C}$ & 0.23 & 0.07 & 0.23 & $0.02^{*}$ \\
$\delta^{15} \mathrm{~N}$ & 0.25 & $0.04^{*}$ & 0.14 & 0.08 \\
Germany & & & & \\
NLFAs & -0.23 & 0.77 & & \\
$\delta^{13} \mathrm{C}$ & -0.24 & 0.76 & 0.29 & 0.19 \\
$\delta^{15} \mathrm{~N}$ & 0.37 & 0.12 & 0.46 & 0.06 \\
\hline
\end{tabular}

4 